\title{
Rare-Earth-Containing Magnetic Liquid Crystals
}

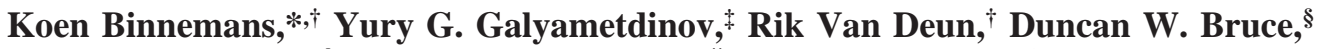 \\ Simon R. Collinson, ${ }^{\S}$ Arkadiy P. Polishchuk,,$"$ Ildar Bikchantaev, ${ }^{\ddagger}$ Wolfgang Haase, ${ }^{\perp}$ \\ Andrey V. Prosvirin, ${ }^{\ddagger}$ Larisa Tinchurina, ${ }^{\ddagger}$ Igor Litvinov, ${ }^{\#}$ Ajdar Gubajdullin, ${ }^{\#}$ \\ Ajdar Rakhmatullin, ${ }^{, I}$ Koen Uytterhoeven, ${ }^{\dagger}$ and Luc Van Meervelt ${ }^{\dagger}$
}

Contribution from the Department of Chemistry, Katholieke Universiteit Leuven, Celestijnenlaan 200F, B-3001 Leuven, Belgium, Physical-Technical Institute, Kazan Branch RAS, Sibirsky Tract 10/7, 420029 Kazan, Russia, School of Chemistry, University of Exeter, Stocker Road,

Exeter EX4 4QD, England, National Technical University of Ukraine, pr. Pobedi 37, 252056 Kiev, Ukraine, Institut für Physikalische Chemie, Technische Universität Darmstadt, Condensed Matter Group, Petersenstrasse 20, D-64287 Darmstadt, Germany, and A. E. Arbuzov Institute of Organic and Physical Chemistry, Arbuzov Str. 8, 420088 Kazan, Russia

Received September 15, 1999. Revised Manuscript Received February 23, 2000

\begin{abstract}
Rare-earth-containing metallomesogens with 4-alkoxy- $N$-alkyl-2-hydroxybenzaldimine ligands are reported. The stoichiometry of the complexes is $\left[\mathrm{Ln}(\mathrm{LH})_{3}\left(\mathrm{NO}_{3}\right)_{3}\right]$, where $\mathrm{Ln}$ is the trivalent rare-earth ion (Y, $\mathrm{La}$, and Pr to Lu, except Pm) and LH is the Schiff base. The Schiff base ligands are in the zwitterionic form and coordinate through the phenolic oxygen only. The three nitrate groups coordinate in a bidentate fashion. The X-ray single-crystal structures of the nonmesogenic homologous complexes [ $\left.\mathrm{Ln}(\mathrm{LH})_{3}\left(\mathrm{NO}_{3}\right)_{3}\right]$, where $\mathrm{Ln}$ $=\mathrm{Nd}(\mathrm{III}), \mathrm{Tb}(\mathrm{III})$, and $\mathrm{Dy}(\mathrm{III})$ and $\mathrm{LH}=\mathrm{CH}_{3} \mathrm{OC}_{6} \mathrm{H}_{3}(2-\mathrm{OH}) \mathrm{CH}=\mathrm{NC}_{4} \mathrm{H}_{9}$, are described. Although the Schiff base ligands do not exhibit a mesophase, the metal complexes do (SmA phase). The mesogenic rare-earth complexes were studied by NMR, IR, EPR, magnetic susceptibility measurements, X-ray diffraction, and molecular modeling. The metal complexes in the mesophase have a very large magnetic anisotropy, so that these magnetic liquid crystals can easily be aligned by an external magnetic field.
\end{abstract}

\section{Introduction}

Liquid crystals are fascinating materials, as they exhibit properties of both solids and liquids. Classic rodlike organic liquid crystals are diamagnetic and can be easily oriented by an electric field. In theory, it is possible to align liquid crystals by a magnetic field, in a manner analogous to alignment in an electric field. Relatively strong magnetic fields are necessary for the alignment of diamagnetic liquid crystals, and this is not compatible with small devices such as displays. In recent years, the design of metal-containing liquid crystals (metallomesogens) has attracted a lot of attention, and this research field is described in several reviews. ${ }^{1}$ By incorporating metal ions with unpaired electrons into liquid crystals, it is possible to create paramagnetic liquid crystals. The required magnetic field strength to align paramagnetic liquid crystals is much smaller than the field strength necessary to align diamagnetic liquid crystals. For alignment by weak magnetic fields, the compounds need to have

\footnotetext{
* Address correspondence to this author.

$\dagger$ Katholieke Universiteit Leuven.

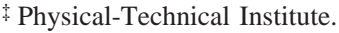

$\S$ University of Exeter.

" National Technical University of Ukraine.

$\perp$ Technische Universität Darmstadt.

\# A. E. Arbuzov Institute of Organic and Physical Chemistry.

Il Kazan State University.

(1) (a) Giroud-Godquin, A. M.; Maitlis, P. M. Angew. Chem., Int. Ed. Engl. 1991, 30, 375. (b) Hudson, S. A.; Maitlis, P. M. Chem. Rev. 1993, 93, 861. (c) Polishchuk, A. P.; Timofeeva, T. V. Russ. Chem. Rev. 1993, 62, 291.(d) Metallomesogens, Synthesis, Properties and Applications; Serrano, J. L., Ed.; VCH: Weinheim, 1996. (e) Bruce, D. W. In Inorganic Materials, 2nd ed.; Bruce, D. W., O’Hare, D., Eds.; Wiley: Chichester, 1996; Chapter 8, p 429. (f) Donnio, B.; Bruce, D. W. Struct. Bond. 1999, 95, 193.
}

a large magnetic anisotropy $\Delta \chi$. The $|\Delta \chi|$ values of diamagnetic liquid crystals range between 0 and $60 \times 10^{-6} \mathrm{~cm}^{3} \mathrm{~mol}^{-1}{ }^{2}$ This value can be increased by introducing a paramagnetic center in the liquid-crystalline compounds. . $^{3,4}$

Our search for magnetic liquid crystals brought us to low molecular weight metallomesogens containing rare-earth (or lanthanide) ions, because these ions often have a large magnetic anisotropy. Only a few examples of rare-earth containing metallomesogens have been described in the literature. The first calamitic (= rodlike) lanthanide-containing metallomesogens were reported by Galyametdinov and co-workers, being a series of mesomorphic lanthanide complexes of liquid-crystalline Schiff base ligands with two aromatic rings. ${ }^{5}$ All the complexes formed a highly viscous smectic mesophase, which was afterward identified as a smectic A phase. Later, Galyametdinov et al. ${ }^{6,7}$ used simpler one-ring Schiff bases LH as the ligand.

(2) Muller, H.; Haase, W. J. Phys. (France) 1983, 44, 1209.

(3) (a) Marcos, A.; Romero, P.; Serrano, J. L.; Barberá, J.; Levelut, A. M. Liq. Cryst. 1990, 7, 251. (b) Haase, W.; Gehring, S.; Borchers, B. Multifunctional Materials. In MRS Symp. Proc. 1990, 175, 249; Buckley, A. J., Gallagher-Daggitt, G., Karasz, F. E., Ulrich, D. R., Eds. (c) Barberá, J.; Levelut, A. M.; Marcos, M.; Romero, P.; Serrano, J. L. Liq. Cryst. 1991, 10, 119. (d) Campillos, E.; Marcos, M.; Serrano, J. L.; Alonso, P. J. J. Mater. Chem. 1991, 1, 197. (e) Haase, W.; Borchers, B. Magnetic Molecular Materials. In NATO ASI Ser. E: Appl. Sci. 1991, 198, 245. (f) Borchers, B.; Haase, W. Mol. Cryst. Liq. Cryst. 1991, 209, 319. (g) Alonso, P. J.; Martínez, J. I. Liq. Cryst. 1996, 21, 597. (h) Deschenaux, R.; Schweissguth, M.; Vilches, M. T.; Levelut, A. M.; Hautot, D.; Long, G. J.; Luneau, D. Organometallics 1999, 18, 5553.

(4) Bikchantaev, I.; Galyametdinov, Yu.; Prosvirin, A.; Griesar, K.; SotoBustamante, E. A.; Haase, W. Liq. Cryst. 1995, 18, 231.

(5) Galyametdinov, Yu. G.; Ivanova, G. I.; Ovchinnikov, I. V. Bull. Acad. Sci. USSR, Div. Chem. Sci. 1991, 40, 1109. 
Although these ligands were not mesomorphic, the corresponding lanthanide complexes were mesomorphic (SmA phase), and the viscosity and transition temperatures of these complexes were much lower than those of earlier described complexes. These complexes were supposed to have the stoichiometry [LnL$(\mathrm{LH})_{2} \mathrm{X}_{2}$ ], showing that one ligand coordinates in its deprotonated form, whereas the other two coordinate as the neutral species. Binnemans et al. ${ }^{8}$ showed that the choice of the counterion has an important influence on the transition temperatures of these complexes with Schiff base ligands. The change of the transition temperatures of Schiff base complexes with the nitrate anion reflects the lanthanide contraction, in the sense that a gradual decrease of the mesophase stability range over the lanthanide series was observed. ${ }^{9,10}$ Magnetic studies on this type of lanthanide-containing metallomesogens were published by Galyametdinov and co-workers. ${ }^{6,11-14} \mathrm{~A}$ huge value for the magnetic birefringence was found for the $\mathrm{Tb}$ complex $\left[\mathrm{TbL}(\mathrm{LH})_{2}\left(\mathrm{NO}_{3}\right)_{2}\right]$, where $\mathrm{LH}$ is the Schiff base $\mathrm{C}_{12} \mathrm{H}_{25}$ $\mathrm{OC}_{6} \mathrm{H}_{3}(2-\mathrm{OH}) \mathrm{CH}=\mathrm{NC}_{18} \mathrm{H}_{37} \cdot{ }^{11}$

In this paper, we describe the structure and magnetic properties of mesogenic rare-earth complexes with 4-(alkoxy)$\mathrm{N}$-alkyl-2-hydroxybenzaldimine Schiff base ligands. The crystal structures of nonmesogenic $\mathrm{Nd}$ (III), $\mathrm{Tb}$ (III), and $\mathrm{Dy}(\mathrm{III})$ complexes with Schiff base ligands were obtained. On the basis of NMR, EPR, and IR data, in combination with molecular modeling, these results are extrapolated to liquid-crystalline rareearth-containing Schiff base complexes. The magnetic alignment of the metal complexes is discussed.

\section{Results}

Synthesis of Rare-Earth Complexes 1-42. The synthesis of the 4-(alkoxy)- $N$-alkyl-2-hydroxybenzaldimine Schiff bases and the rare-earth complexes $\mathbf{1 - 4 2}$ is summarized in Scheme 1. A summary of the rare-earth complexes can be found in Table 1. The stoichiometry of the complexes is consistent with the formula $\left[\mathrm{Ln}(\mathrm{LH})_{3}\left(\mathrm{NO}_{3}\right)_{3}\right]$. The $\mathrm{CHN}$ analysis data of the ligands and complexes, together with the melting points of the ligands, are available as Supporting Information.

Crystal Structures of Complexes 1-3. The X-ray singlecrystal structure was determined for the Dy(III) $\mathbf{1}$ and the Nd(III) complex 2. For the $\mathrm{Tb}$ (III) complex $\mathbf{3}$ the unit cell parameters were determined. These complexes have short alkyl chains, but it is supposed that the coordination sphere is unaltered by increasing the chain lengths.

The Dy(III) complex $\mathbf{1}$ crystallizes in the triclinic system (space group P $\overline{1}$, No. 2), with two formula units in the unit cell. The crystallographic data are summarized in Table 2, and

(6) Galyametdinov, Yu. G.; Ivanova, G. I.; Prosvirin, A. V.; Kadkin, O. Russ. Chem. Bull. 1994, 43, 938.

(7) Galyametdinov, Yu. G.; Athanassopoulou, M. A.; Griesar, K.; Kharitonova, O.; Soto Bustamante, E. A.; Tinchurina, L.; Ovchinnikov, I.; Haase, W. Chem. Mater. 1996, 8, 922.

(8) Binnemans, K.; Galyametdinov, Yu. G.; Collinson, S. R.; Bruce, D. W. J. Mater. Chem. 1998, 8, 1551.

(9) Binnemans, K.; Van Deun, R.; Galyametdinov, Yu. G.; Bruce, D. W. Chem. Phys. Lett. 1999, 300, 509.

(10) Binnemans, K.; Bruce D. W.; Collinson, S. R.; Van Deun, R.; Galyametdinov, Yu. G.; Martin, F. Philos. Trans. R. Soc. London A 1999, $357,3063$.

(11) Galyametdinov, Yu. G.; Athanassopoulo, M.; Haase, W.; Ovchinnikov, I. V. Russ. J. Coord. Chem. 1995, 21, 718.

(12) Ovchinnikov, I. V.; Galyametdinov, Yu. G.; Prosvirin, A. V. Russ. Chem. Bull. 1995, 44, 768.

(13) Galyametdinov, Yu. G.; Ivanova, G.; Ovchinnikov, I.; Prosvirin, A.; Guillon, D.; Heinrich, B.; Dunmur, D. A.; Bruce, D. W. Liq. Cryst. 1996, 20, 831 .

(14) Turanov, A. N.; Ovchinnikov, I. V.; Galyametdinov, Yu. G.; Ivanova, G. I.; Goncharov, V. A. Russ. Chem. Bull. 1999, 48, 690.
Scheme 1. Synthesis of the Schiff Base Ligands and Their Rare-Earth Complexes ${ }^{a}$

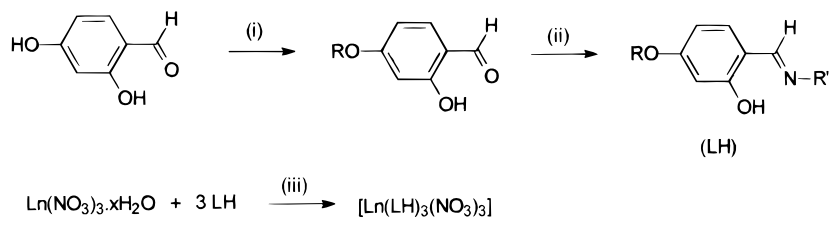

${ }^{a}$ Reaction conditions: (i) $\mathrm{RBr}$ (1 equiv), $\mathrm{KHCO}_{3}$ (1 equiv), DMF, reflux ( $3 \mathrm{~h}$ ); (ii) $\mathrm{R}^{\prime} \mathrm{NH}_{2}$ (1 equiv), acetic acid (catalyst, 5 drops), absolute ethanol, reflux ( $3 \mathrm{~h}$ ); (iii) absolute ethanol, room temperature, $2 \mathrm{~h}$. Modifications of step (i) for ligands with short alkoxy chains are described in the Experimental Section

the atomic positions are available as Supporting Information. The Dy atom lies in a general position and the metal atom is coordinated by three bidentate nitrate groups, while the three neutral Schiff base ligands coordinate in a monodentate fashion via the phenolic oxygen. The nitrogen atom of the Schiff base remains noncoordinated. The nearest environment of the Dy atom consists of three oxygen atoms of the neutral Schiff base ligands and six oxygen atoms of the nitrate groups (Figure 1). In this way, the Dy atom is in a nine-coordinate environment. The coordination polyhedron is a distorted monocapped square antiprism. The dihedral angle between planes of any two nitrate groups in complex 1 is approximately $90^{\circ}\left(79-87^{\circ}\right)$. A special feature of the crystal structure is that the Schiff bases coordinate as neutral ligands to the Dy atom. However, the oxygen atoms of the $\mathrm{OH}$ group are deprotonated and the hydrogen atoms have moved to the nitrogen atom. In this way, a zwitterionic structure is formed (negative charge on the oxygen atom, positive charge on the imine nitrogen atom). Intramolecular H-bonds $\mathbf{N}-\mathbf{H} \cdots \mathbf{O}$ exist between the protonated nitrogen and the deprotonated oxygen atoms. Two of the three hydrogen atoms form a second $\mathrm{H}$-bond with an oxygen atom of a nitrate group. The six-membered rings closed by intraligand $\mathrm{H}$-bonds are planar (root-mean-square deviations 0.005-0.024 $\AA$ ) and virtually coplanar with the benzene rings (deviation from planarity is $1.5-2.3^{\circ}$ ).

The crystal structure of the $\mathrm{Nd}(\mathrm{III})$ complex $\left[\mathrm{Nd}\left(\mathrm{L}^{1} \mathrm{H}\right)_{3}-\right.$ $\left(\mathrm{NO}_{3}\right)_{3}$ ] (2) is very similar to the crystal structure of the corresponding Dy(III) complex 1. Because the $\mathrm{Nd}(\mathrm{III})$ ion has a slightly larger ionic radius than the Dy(III), the unit cell volume of the $\mathrm{Nd}(\mathrm{III})$ complex $\mathbf{2}$ is larger than the unit cell volume of the Dy(III) complex 1. The same trend is of course observed for the cell parameters $a, b$, and $c$ (Table 2). The analogous $\mathrm{Tb}(\mathrm{III})$ compound $\mathbf{3}$ proved to be isostructural with the $\mathrm{Nd}(\mathrm{III})$ and $\mathrm{Dy}(\mathrm{III})$ compounds. The cell parameters of [Tb$\left.\left(\mathrm{L}^{1} \mathrm{H}\right)_{3}\left(\mathrm{NO}_{3}\right)_{3}\right]$ are $a=11.372(2) \AA, b=13.777(1) \AA, c=$ 14.035(1) $\AA, \alpha=98.647(8)^{\circ}, \beta=98.29(1)^{\circ}, \gamma=92.68(1)^{\circ}$, and $V=2145.9(5) \AA^{3}$. From these results, we can conclude that the rare-earth complexes of the type $\left[\mathrm{Ln}\left(\mathrm{L}^{1} \mathrm{H}\right)_{3}\left(\mathrm{NO}_{3}\right)_{3}\right]$ are isostructural, at least for the elements of the middle of the lanthanide series. Calculations have shown that the packing of the atoms in the crystal structures of compounds $\mathbf{1}, \mathbf{2}$, and $\mathbf{3}$ is very dense.

Thermal Behavior of the Rare-Earth Complexes. The 4-alkoxy- $N$-octadecyl-2-hydroxybenzaldimine Schiff bases themselves are not mesomorphic. All the rare-earth complexes, except complexes 1-3, exhibit a mesophase, the mesophase being identified as a smectic A phase by hot-stage polarized optical microscopy (Table 2). The presence of this mesophase type was also proved by high-temperature X-ray diffraction on an analogous compound. ${ }^{13}$ The mesophase is highly viscous, but more fluid than the mesophase of the previously described 
Table 1. Overview of the Rare-Earth Complexes $\left[\mathrm{Ln}(\mathrm{LH})_{3}\left(\mathrm{NO}_{3}\right)_{3}\right]$ and Their Thermal Behavior ${ }^{a}$

\begin{tabular}{|c|c|c|c|c|c|c|c|}
\hline \multirow[b]{2}{*}{ complex } & \multirow[b]{2}{*}{$\mathrm{R}$} & \multirow[b]{2}{*}{$\mathrm{R}^{\prime}$} & \multirow[b]{2}{*}{ metal ion } & \multicolumn{2}{|c|}{$\mathrm{Cr} \rightarrow \mathrm{SmA}^{c}$} & \multicolumn{2}{|c|}{$\mathrm{SmA} \rightarrow \mathrm{I}^{c}$} \\
\hline & & & & $T\left({ }^{\circ} \mathrm{C}\right)$ & $\Delta H\left(\mathrm{~kJ} \mathrm{~mol}^{-1}\right)$ & $T\left({ }^{\circ} \mathrm{C}\right)$ & $\Delta H\left(\mathrm{~kJ} \mathrm{~mol}^{-1}\right)$ \\
\hline $\mathbf{1}^{b}$ & $\mathrm{CH}_{3}$ & $\mathrm{C}_{4} \mathrm{H}_{9}$ & Dy(III) & & n.d. ${ }^{d}$ & & n.d. \\
\hline $2^{b}$ & $\mathrm{CH}_{3}$ & $\mathrm{C}_{4} \mathrm{H}_{9}$ & $\mathrm{Nd}(\mathrm{III})$ & & n.d. & & n.d. \\
\hline $\mathbf{3}^{b}$ & $\mathrm{CH}_{3}$ & $\mathrm{C}_{4} \mathrm{H}_{9}$ & $\mathrm{~Tb}(\mathrm{III})$ & & n.d. & & n.d. \\
\hline 4 & $\mathrm{C}_{8} \mathrm{H}_{17}$ & $\mathrm{C}_{18} \mathrm{H}_{37}$ & $\mathrm{Y}(\mathrm{III})$ & 132 & 22.7 & 141 & 11.0 \\
\hline 5 & $\mathrm{C}_{8} \mathrm{H}_{17}$ & $\mathrm{C}_{18} \mathrm{H}_{37}$ & $\mathrm{La}(\mathrm{III})$ & 83 & 2.5 & 165 & 11.8 \\
\hline 6 & $\mathrm{C}_{8} \mathrm{H}_{17}$ & $\mathrm{C}_{18} \mathrm{H}_{37}$ & $\operatorname{Pr}(\mathrm{III})$ & 90 & 8.7 & 163 & 13.2 \\
\hline 7 & $\mathrm{C}_{8} \mathrm{H}_{17}$ & $\mathrm{C}_{18} \mathrm{H}_{37}$ & $\mathrm{Nd}(\mathrm{III})$ & 98 & 15.0 & 159 & 11.8 \\
\hline 8 & $\mathrm{C}_{8} \mathrm{H}_{17}$ & $\mathrm{C}_{18} \mathrm{H}_{37}$ & $\mathrm{Sm}(\mathrm{III})$ & 105 & 12.4 & 154 & 12.4 \\
\hline 9 & $\mathrm{C}_{8} \mathrm{H}_{17}$ & $\mathrm{C}_{18} \mathrm{H}_{37}$ & $\mathrm{Eu}(\mathrm{III})$ & 108 & 15.5 & 151 & 13.3 \\
\hline 10 & $\mathrm{C}_{8} \mathrm{H}_{17}$ & $\mathrm{C}_{18} \mathrm{H}_{37}$ & Gd(III) & 121 & 16.9 & 150 & 12.7 \\
\hline 11 & $\mathrm{C}_{8} \mathrm{H}_{17}$ & $\mathrm{C}_{18} \mathrm{H}_{37}$ & $\mathrm{~Tb}(\mathrm{III})$ & 128 & 17.6 & 148 & 10.6 \\
\hline 12 & $\mathrm{C}_{8} \mathrm{H}_{17}$ & $\mathrm{C}_{18} \mathrm{H}_{37}$ & Dy(III) & 131 & 21.4 & 146 & 11.8 \\
\hline 13 & $\mathrm{C}_{8} \mathrm{H}_{17}$ & $\mathrm{C}_{18} \mathrm{H}_{37}$ & Ho(III) & 134 & 22.2 & 144 & 10.8 \\
\hline 14 & $\mathrm{C}_{8} \mathrm{H}_{17}$ & $\mathrm{C}_{18} \mathrm{H}_{37}$ & $\operatorname{Er}(\mathrm{III})$ & 135 & n.d. & 142 & n.d. \\
\hline 15 & $\mathrm{C}_{8} \mathrm{H}_{17}$ & $\mathrm{C}_{18} \mathrm{H}_{37}$ & $\operatorname{Tm}(\mathrm{III})$ & 139 & n.d. & 142 & n.d. \\
\hline 16 & $\mathrm{C}_{8} \mathrm{H}_{17}$ & $\mathrm{C}_{18} \mathrm{H}_{37}$ & $\mathrm{Yb}(\mathrm{III})$ & 138 & n.d. & 141 & n.d. \\
\hline 17 & $\mathrm{C}_{8} \mathrm{H}_{17}$ & $\mathrm{C}_{18} \mathrm{H}_{37}$ & $\mathrm{Lu}(\mathrm{III})$ & 135 & n.d. & 139 & n.d. \\
\hline 18 & $\mathrm{CH}_{3}$ & $\mathrm{C}_{18} \mathrm{H}_{37}$ & $\mathrm{Nd}(\mathrm{III})$ & 119 & 37.9 & 127 & 3.8 \\
\hline 19 & $\mathrm{C}_{2} \mathrm{H}_{5}$ & $\mathrm{C}_{18} \mathrm{H}_{37}$ & $\mathrm{Nd}(\mathrm{III})$ & 132 & 21.9 & 147 & 7.3 \\
\hline 20 & $\mathrm{C}_{3} \mathrm{H}_{7}$ & $\mathrm{C}_{18} \mathrm{H}_{37}$ & $\mathrm{Nd}(\mathrm{III})$ & 112 & 15.6 & 149 & 8.9 \\
\hline 21 & $\mathrm{C}_{4} \mathrm{H}_{9}$ & $\mathrm{C}_{18} \mathrm{H}_{37}$ & $\mathrm{Nd}(\mathrm{III})$ & 119 & 14.0 & 158 & 10.4 \\
\hline 22 & $\mathrm{C}_{5} \mathrm{H}_{11}$ & $\mathrm{C}_{18} \mathrm{H}_{37}$ & $\mathrm{Nd}(\mathrm{III})$ & 115 & 15.7 & 155 & 10.9 \\
\hline 23 & $\mathrm{C}_{6} \mathrm{H}_{13}$ & $\mathrm{C}_{18} \mathrm{H}_{37}$ & $\mathrm{Nd}(\mathrm{III})$ & 110 & 13.7 & 156 & 11.5 \\
\hline 24 & $\mathrm{C}_{7} \mathrm{H}_{15}$ & $\mathrm{C}_{18} \mathrm{H}_{37}$ & $\mathrm{Nd}(\mathrm{III})$ & 104 & 13.7 & 155 & 11.3 \\
\hline 25 & $\mathrm{C}_{9} \mathrm{H}_{19}$ & $\mathrm{C}_{18} \mathrm{H}_{37}$ & $\mathrm{Nd}(\mathrm{III})$ & 100 & 15.4 & 158 & 11.4 \\
\hline 26 & $\mathrm{C}_{10} \mathrm{H}_{21}$ & $\mathrm{C}_{18} \mathrm{H}_{37}$ & $\mathrm{Nd}(\mathrm{III})$ & 101 & 16.8 & 158 & 11.0 \\
\hline 27 & $\mathrm{C}_{11} \mathrm{H}_{23}$ & $\mathrm{C}_{18} \mathrm{H}_{37}$ & $\mathrm{Nd}(\mathrm{III})$ & 103 & 16.9 & 157 & 10.8 \\
\hline 28 & $\mathrm{C}_{12} \mathrm{H}_{25}$ & $\mathrm{C}_{18} \mathrm{H}_{37}$ & $\mathrm{Nd}(\mathrm{III})$ & 100 & 15.5 & 158 & 11.7 \\
\hline 29 & $\mathrm{C}_{13} \mathrm{H}_{27}$ & $\mathrm{C}_{18} \mathrm{H}_{37}$ & $\mathrm{Nd}(\mathrm{III})$ & 100 & 11.0 & 158 & 11.7 \\
\hline 30 & $\mathrm{C}_{14} \mathrm{H}_{29}$ & $\mathrm{C}_{18} \mathrm{H}_{37}$ & $\mathrm{Nd}(\mathrm{III})$ & 102 & 15.5 & 155 & 10.9 \\
\hline 31 & $\mathrm{C}_{15} \mathrm{H}_{31}$ & $\mathrm{C}_{18} \mathrm{H}_{37}$ & $\mathrm{Nd}(\mathrm{III})$ & 103 & 15.3 & 154 & 10.8 \\
\hline 32 & $\mathrm{C}_{16} \mathrm{H}_{33}$ & $\mathrm{C}_{18} \mathrm{H}_{37}$ & $\mathrm{Nd}(\mathrm{III})$ & 103 & 16.4 & 152 & 10.7 \\
\hline 33 & $\mathrm{C}_{17} \mathrm{H}_{35}$ & $\mathrm{C}_{18} \mathrm{H}_{37}$ & $\mathrm{Nd}(\mathrm{III})$ & 104 & 19.0 & 150 & 10.4 \\
\hline 34 & $\mathrm{C}_{18} \mathrm{H}_{37}$ & $\mathrm{C}_{18} \mathrm{H}_{37}$ & $\mathrm{Nd}(\mathrm{III})$ & 101 & 15.1 & 150 & 10.1 \\
\hline 35 & $\mathrm{C}_{19} \mathrm{H}_{39}$ & $\mathrm{C}_{18} \mathrm{H}_{37}$ & $\mathrm{Nd}(\mathrm{III})$ & 101 & 19.7 & 146 & 10.3 \\
\hline 36 & $\mathrm{C}_{20} \mathrm{H}_{41}$ & $\mathrm{C}_{18} \mathrm{H}_{37}$ & $\mathrm{Nd}(\mathrm{III})$ & 100 & 19.6 & 144 & 10.1 \\
\hline 37 & $\mathrm{C}_{12} \mathrm{H}_{25}$ & $\mathrm{C}_{18} \mathrm{H}_{37}$ & $\mathrm{La}(\mathrm{III})$ & 81 & 3.7 & 138 & 10.3 \\
\hline 38 & $\mathrm{C}_{12} \mathrm{H}_{25}$ & $\mathrm{C}_{16} \mathrm{H}_{33}$ & $\operatorname{Pr}(\mathrm{III})$ & 105 & n.d. & 148 & n.d. \\
\hline 39 & $\mathrm{C}_{12} \mathrm{H}_{25}$ & $\mathrm{C}_{16} \mathrm{H}_{33}$ & $\mathrm{Nd}(\mathrm{III})$ & 105 & n.d. & 147 & n.d. \\
\hline 40 & $\mathrm{C}_{12} \mathrm{H}_{25}$ & $\mathrm{C}_{16} \mathrm{H}_{33}$ & Gd(III) & 107 & n.d. & 145 & n.d. \\
\hline 41 & $\mathrm{C}_{12} \mathrm{H}_{25}$ & $\mathrm{C}_{16} \mathrm{H}_{33}$ & $\mathrm{~Tb}$ (III) & 107 & n.d. & 147 & n.d. \\
\hline 42 & $\mathrm{C}_{12} \mathrm{H}_{25}$ & $\mathrm{C}_{16} \mathrm{H}_{33}$ & $\operatorname{Er}(\mathrm{III})$ & 107 & n.d. & 147 & n.d. \\
\hline
\end{tabular}

${ }^{a} \mathrm{LH}$ is the Schiff base ligand with alkoxy chain $\mathrm{R}$ and $N$-alkyl chain $\mathrm{R}^{\prime}$ (see Scheme 1 ). ${ }^{b}$ Not mesomorphic. ${ }^{c} \mathrm{Cr}$ : crystalline phase. SmA: smectic A phase. I: isotropic liquid. ${ }^{d}$ n.d. not determined.

complexes of the two-ring Schiff base ligands. ${ }^{5}$ The viscosity gradually decreases at higher temperatures, and a strong increase in fluidity is observed close to the clearing point. When cooling the mesophase, no crystallization is observed in the microscope and the texture of the mesophase is frozen into the solid state, forming a glassy mesophase. The small values of the melting enthalpies of the complexes in the second heating run of the DSC-thermogram indicate that the compounds only crystallize partially (Table 2).

The rare-earth complexes of ligand $\mathrm{L}^{9} \mathrm{H}$ show very clearly that a correlation exists between the ionic radius and the transition temperatures. The ionic size decreases over the lanthanide series (lanthanide contraction), and simultaneously, the mesophase stability range decreases. This correlation is also illustrated by the fact that the yttrium complex $\mathbf{4}$ and the holmium complex $\mathbf{1 3}$ have very comparable transition temperatures, in agreement with the nearly identical ionic size. Since the ion gets smaller over the lanthanide series and the charge remains, the electrostatic attraction between the lanthanide ion and the coordinating groups becomes stronger and therefore the melting temperature increases. It is more difficult to explain the reduction of the clearing point over the lanthanide series.
Probably the reduction in ion size leads to steric problems in the arrangement of the ligands around the complexes and thus more structural distortions occur, leading to a less anisotropic complex and reduction of the clearing point. Because of the overlap between melting and clearing peaks, the melting and clearing enthalpy could not be determined separately for the complexes at the end of the lanthanide series ( $\mathrm{Er}-\mathrm{Lu})$.

For investigating the influence of the alkoxy chain length on the transition temperatures of the mesogenic Schiff base complexes, we prepared the $\mathrm{Nd}$ (III) complexes of the Schiff base ligands $\mathrm{L}^{2} \mathrm{H}$ to $\mathrm{L}^{21} \mathrm{H}$, giving all the alkyl chains between $\mathrm{CH}_{3} \mathrm{O}$ and $\mathrm{C}_{20} \mathrm{H}_{41} \mathrm{O}$. The $N$-alkyl chain was fixed to $\mathrm{C}_{18} \mathrm{H}_{37}$. All the $\mathrm{Nd}$ (III) complexes were found to be liquid crystals, even the complexes with the shortest chain lengths. However, the alkoxy chain length of the ligand has less influence on the transition temperatures than the rare-earth ion has. The transition temperatures of the $\mathrm{Nd}(\mathrm{III})$ complexes of the different ligands are rather constant for the different alkoxy chain lengths (Figure 2 ); for the shortest alkoxy chain lengths a smooth variation is absent. The octadecyl chain on the imine nitrogen provides enough structural anisotropy to the complexes (i.e., a high length/width ratio) so that the complexes behave as calamitic 
Table 2. Summary of Crystal Data, Intensity Measurements, and Structure Refinement for $\left[\mathrm{Dy}\left(\mathrm{L}^{1} \mathrm{H}\right)_{3}\left(\mathrm{NO}_{3}\right)_{3}\right](\mathbf{1})$ and $\left[\mathrm{Nd}\left(\mathrm{L}^{1} \mathrm{H}\right)_{3}\left(\mathrm{NO}_{3}\right)_{3}\right](\mathbf{2})$

\begin{tabular}{|c|c|c|}
\hline & {$\left[\mathrm{Dy}\left(\mathrm{L}^{1} \mathrm{H}\right)_{3}\left(\mathrm{NO}_{3}\right)_{3}\right](\mathbf{1})$} & {$\left[\mathrm{Nd}\left(\mathrm{L}^{1} \mathrm{H}\right)_{3}\left(\mathrm{NO}_{3}\right)_{3}\right](\mathbf{2})$} \\
\hline formula & $\mathrm{C}_{36} \mathrm{H}_{51} \mathrm{~N}_{6} \mathrm{O}_{15} \mathrm{Dy}$ & $\mathrm{C}_{36} \mathrm{H}_{51} \mathrm{~N}_{6} \mathrm{O}_{15} \mathrm{Nd}$ \\
\hline mol wt & 970.31 & 952.05 \\
\hline cryst syst & triclinic & triclinic \\
\hline space group & $P \overline{1}($ No. 2$)$ & $P \overline{1}$ (No. 2) \\
\hline$a, \AA$ & $11.380(1)$ & $11.455(2)$ \\
\hline$b, \AA$ & $13.800(5)$ & $13.859(3)$ \\
\hline$c, \AA$ & $14.027(5)$ & $14.101(4)$ \\
\hline$\alpha, \operatorname{deg}$ & $98.70(3)$ & $98.50(2)$ \\
\hline$\beta, \operatorname{deg}$ & $98.15(2)$ & $98.87(1)$ \\
\hline$\gamma, \operatorname{deg}$ & $92.67(2)$ & $92.52(2)$ \\
\hline$V, \AA^{3}$ & $2150(1)$ & $2182.4(9)$ \\
\hline$Z$ & 2 & 2 \\
\hline$D_{\text {calc }}, \mathrm{g} \cdot \mathrm{cm}^{-3}$ & 1.498 & 1.449 \\
\hline$F(000)$ & 990 & 978 \\
\hline$\mu_{\mathrm{MoK} \alpha}, \mathrm{cm}^{-1}$ & 1.81 & 1.85 \\
\hline reflns measd & 13477 & 7708 \\
\hline$\theta$ range $(\mathrm{deg})$ & $2<\theta<26$ & $2<\theta<25$ \\
\hline no. of unique reflcns & 10305 & 7328 \\
\hline no. of reflcns obsd ${ }^{a}$ & 9711 & 6418 \\
\hline no. of variables & 728 & 566 \\
\hline$R$ & 0.0250 & 0.0376 \\
\hline
\end{tabular}

${ }^{a} I>3 \sigma(I)$ for the Dy(III) complex, $I>2 \sigma(I)$ for the Nd(III) complex.

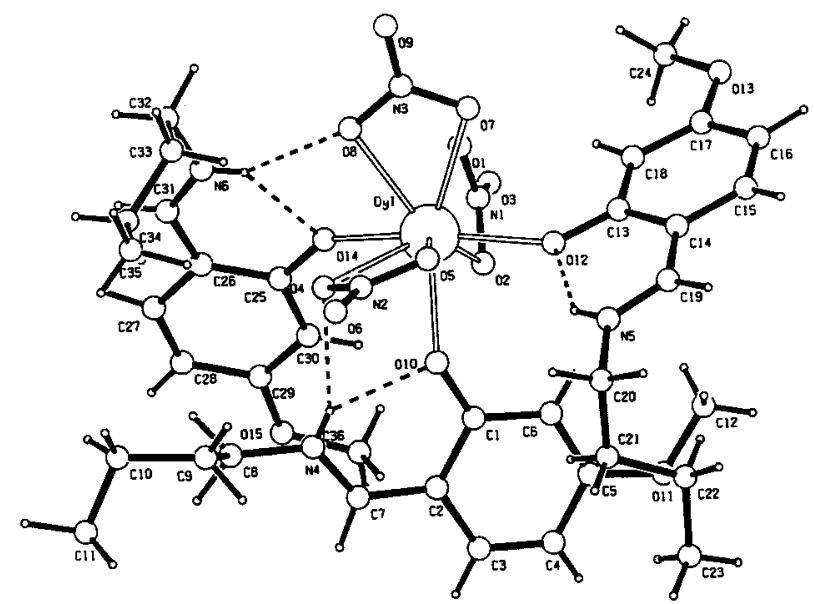

Figure 1. Crystal structure of complex $\left[\mathrm{Dy}\left(\mathrm{L}^{1} \mathrm{H}\right)_{3}\left(\mathrm{NO}_{3}\right)_{3}\right](\mathbf{1})$.

mesogens and are able to form a smectic A phase. The thermal stability of the metal complexes was studied by thermogravimetry. All the samples which were examined indicate a high thermal stability of the complexes: the complexes only start to decompose above $300{ }^{\circ} \mathrm{C}$ (more than $100{ }^{\circ} \mathrm{C}$ above the clearing point).

Structure of the Mesogenic Rare-Earth Complexes. Because single crystals of Schiff bases with long alkyl chains and single crystals of the corresponding complexes could not be obtained, we were forced to probe the structure of these compounds by means of spectroscopic methods (IR, NMR, and EPR), and by molecular modeling. We made the assumption that extension of the chain lengths of the Schiff base ligands has only a minor effect on the first coordination sphere of the trivalent rare-earth ion. Of course, the chain length will have a significant effect on the packing of the complexes in the crystal structure.

In the infrared spectra of the rare-earth complexes, the $\mathrm{C}=\mathrm{N}$ stretching vibration is shifted to higher wavenumbers (by 30$40 \mathrm{~cm}^{-1}$ to about $1662 \mathrm{~cm}^{-1}$ ) in comparison to the same transition in the Schiff base ligands. This behavior is opposite to what is observed for copper(II) Schiff base complexes in

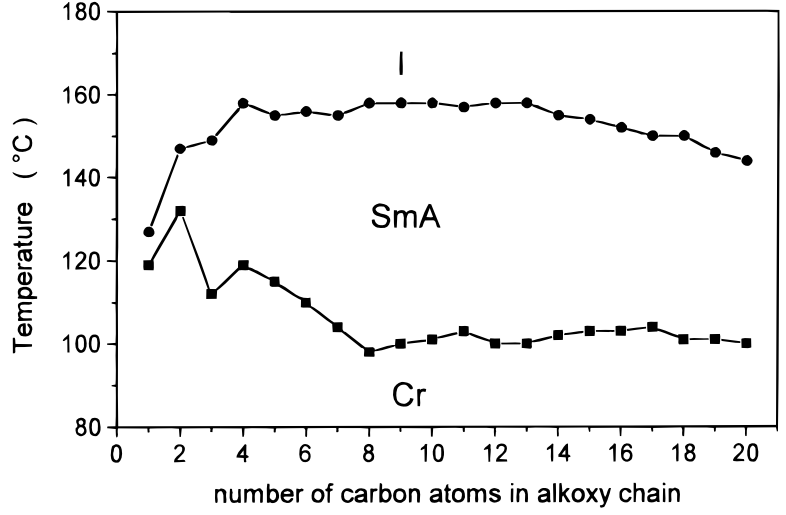

Figure 2. Evolution of the transition temperatures of the $\left[\mathrm{Nd}(\mathrm{LH})_{3}\right.$ $\left(\mathrm{NO}_{3}\right)_{3}$ ] complexes as a function of the alkoxy chain length.

which the deprotonated Schiff base coordinates via the phenolic oxygen and via the azomethine nitrogen to the copper(II) ion. ${ }^{15}$ In these copper(II) complexes, the $\mathrm{C}=\mathrm{N}$ stretching vibration is shifted to lower wavenumbers, indicating less double-bond character in the $\mathrm{C}=\mathrm{N}$ bond. The broad weak $\mathrm{O}-\mathrm{H}$ stretching vibration of the ligand at ca. $2850 \mathrm{~cm}^{-1}$ (on which the $\mathrm{CH}$ modes are superimposed) is replaced in the metal complexes by a band at ca. $3300 \mathrm{~cm}^{-1}$, due to the $\mathrm{N}-\mathrm{H}$ vibration in $\mathrm{C}=$ $\mathrm{N}^{+}-\mathrm{H}$. The broadness of the band shows that this hydrogen atom is still involved in intramolecular H-bonding with the phenolic oxygen. The phenolic $\mathrm{C}-\mathrm{O}$ stretching vibration, which is observed in the Schiff base ligands around $1280 \mathrm{~cm}^{-1}$, overlaps in the metal complexes with a vibration due to the nitrate groups. Four bands in the IR spectra of the complexes near $1475,1283,1120$, and $850 \mathrm{~cm}^{-1}$ can be assigned to vibrations of the coordinated nitrate group (respectively the vibrations $v_{4}, v_{1}, v_{2}$, and $v_{6}$ ). The difference between the $v_{4}$ and the $v_{1}$ peak positions is ca. $190 \mathrm{~cm}^{-1}$, which is typical for bidentate nitrate groups (monodentate nitrate groups display a much smaller splitting).

${ }^{1} \mathrm{H}$ and ${ }^{13} \mathrm{C}$ NMR investigations were carried out both in solution and in the solid state on the ligand $\mathrm{L}^{13} \mathrm{H}$ and on the diamagnetic $\mathrm{La}(\mathrm{III})$ complex $\left[\mathrm{La}\left(\mathrm{L}^{13} \mathrm{H}\right)_{3}\left(\mathrm{NO}_{3}\right)_{3}\right]$ (37). The analysis of the ${ }^{1} \mathrm{H}$ NMR data of these compounds in solution $\left(\mathrm{CDCl}_{3}\right)$ is consistent with the composition $\left[\mathrm{La}\left(\mathrm{L}^{13} \mathrm{H}\right)_{3}\left(\mathrm{NO}_{3}\right)_{3}\right]$ of the lanthanum complex. The signal corresponding to the imine proton $(\mathrm{CH}=\mathrm{N})$ in the complex $(\delta=7.63 \mathrm{ppm})$ is much broader than that in the ligand $(\delta=7.18 \mathrm{ppm})$. For other La(III) complexes, we sometimes even observed a splitting of the imine proton signal. In the ligand $\mathrm{L}^{13} \mathrm{H}$, the signal of the phenolic proton $(\mathrm{OH})$ is found at $\delta=13.80 \mathrm{ppm}$. In the La(III) complex 37, the signal seems to be shifted to $\delta=12.29$ $\mathrm{ppm}$. The relative integrated intensity of this signal corresponds to three protons. However, we found that selective irradiation of the signal at $\delta=12.29 \mathrm{ppm}$ removed the broadening of the imine signal. This proves that the protons are coupled. Thus, the signal at $\delta=12.29 \mathrm{ppm}$ does not correspond to the proton of the $\mathrm{OH}$ group, but to the proton of the $=\mathrm{N}^{+} \mathrm{H}$ group. In the ${ }^{1} \mathrm{H}$ NMR spectrum at $293 \mathrm{~K}$, the value of the coupling constant ${ }^{3} J=10.3 \mathrm{~Hz}$ points to a trans-disposition of the $-\mathrm{CH}=$ and $=\mathrm{N}^{+} \mathrm{H}-$ protons. ${ }^{16}$ An increase in the temperature leads to a broadening of the signal of the $\mathrm{CH}=\mathrm{N}$ proton in the ligand from $4.1 \mathrm{~Hz}$ at $293 \mathrm{~K}$ to $13.7 \mathrm{~Hz}$ at $333 \mathrm{~K}$. The ${ }^{13} \mathrm{C} \mathrm{NMR}$ spectra of the ligand $\mathrm{L}^{13} \mathrm{H}$ and the corresponding $\mathrm{La}(\mathrm{III})$ complex in solution (acetone- $d_{6}$ ) were compared with the ${ }^{13} \mathrm{C} \mathrm{CP} / \mathrm{MAS}$ NMR spectra of these compounds in the solid state at room

(15) Kovacic, J. E. Spectrochim. Acta 1967, 23A, 183.

(16) Bystrov, V. F. Prog. NMR Spectrosc. 1976, 10, 41. 
temperature. For both ligand $\mathrm{L}^{13} \mathrm{H}$ and the corresponding La(III) derivative $\mathbf{3 7}$ the chemical shifts in the powder spectra are very similar to the chemical shifts in the solution spectra, indicating that the magnetic fields surrounding the structure in solution and in the solid state are comparable.

The structure of the SmA phase of a Dy(III)-containing metallomesogen was simulated by molecular modeling. The atomic positions of the Dy(III) complex $\mathbf{1}$ were taken as a starting point. Small-angle X-ray diffraction studies ${ }^{11,13}$ have shown that the thickness of the SmA layers in compound [Tb$\left.\left(\mathrm{L}^{13} \mathrm{H}\right)_{3}\left(\mathrm{NO}_{3}\right)_{3}\right](31.1 \AA)$ is substantially less than the overall length of this complex, being ca. $49 \AA$. The simulation of a probable form of the mesogenic complex $\left[\mathrm{Dy}\left(\mathrm{L}^{13} \mathrm{H}\right)_{3}\left(\mathrm{NO}_{3}\right)_{3}\right]$ was carried out with the assumption that the coordination of the Dy(III) ion in the solid state is retained in the liquidcrystalline (LC) state. Therefore in the complex $\left[\mathrm{Dy}\left(\mathrm{L}^{13} \mathrm{H}\right)_{3^{-}}\right.$ $\left.\left(\mathrm{NO}_{3}\right)_{3}\right]$ the optimization of the geometry of the metal unit was not made, i.e., the mutual arrangement of the (Dy, O,N) atoms in the metal unit remained unaltered. The geometry of complex 1 was optimized, and then we added the missing links of alkyl tails to obtain the complex $\left[\mathrm{Dy}\left(\mathrm{L}^{13} \mathrm{H}\right)_{3}\left(\mathrm{NO}_{3}\right)_{3}\right]$. The main difference in the optimized structure of the central fragments of complexes 1 and $\left[\mathrm{Dy}\left(\mathrm{L}^{13} \mathrm{H}\right)_{3}\left(\mathrm{NO}_{3}\right)_{3}\right]$ is the various orientations of the phenyl rings; the phenyl rings in the mesogenic complex are nearly parallel to each other, in contradistinction to the phenyl rings in $\mathbf{1}$. The overall shape of the complex is rodlike, with a bulge due to the nitrate groups coordinated to the dysprosium atom. A slightly steplike curvature in the rod explains why the overall calculated length of the complex with the alkyl chains in the all-trans conformation is longer than the experimental layer distance. All the alkoxy chains are situated at the same side of the complex (and the same holds for the $\mathrm{N}$-alkyl chains). The thickness of the layers is determined by the long alkyl tails of the ligands and exactly equal to the distance between the Dy atoms of the adjacent layers. Taking into account the close electronic nature of the $\mathrm{Tb}$ and $\mathrm{Dy}$ atoms, it is possible to expect that the central fragment in mesogenic complex $\left[\mathrm{Tb}\left(\mathrm{L}^{13} \mathrm{H}\right)_{3}\left(\mathrm{NO}_{3}\right)_{3}\right]$ is similar to the fragment in complex $\left[\mathrm{Dy}\left(\mathrm{L}^{13} \mathrm{H}\right)_{3}\left(\mathrm{NO}_{3}\right)_{3}\right]$. The layer periodicity of the SmA phase of $\left[\mathrm{Tb}\left(\mathrm{L}^{13} \mathrm{H}\right)_{3}\left(\mathrm{NO}_{3}\right)_{3}\right]$ was calculated for the optimized structure to be $30.3 \AA$. This magnitude correlates well with the experimentally determined periodicity of the layer in the mesophase of compound $\left[\mathrm{Tb}\left(\mathrm{L}^{13} \mathrm{H}\right)_{3}\left(\mathrm{NO}_{3}\right)_{3}\right]$, being $31.1 \AA .7$

\section{Magnetic and Magnetooptical Properties}

To obtain additional information on the structure of the metallomesogenic complexes and to investigate the magnetic anisotropy, we carried out temperature-dependent magnetic susceptibility and magnetic birefringence measurements. The molar magnetic susceptibility $\chi_{M}$ (hereafter abbreviated to $\chi$ ) of a free metal ion, with total angular momentum $J$, in the ground state is

$$
\chi_{\mathrm{M}}=\frac{N_{\mathrm{A}} g_{\mathrm{J}}^{2} \mu_{\mathrm{B}}^{2}}{3 k(T-\Theta)} J(J+1)
$$

where $N_{\mathrm{A}}$ is Avogadro's number, $\mu_{\mathrm{B}}$ is the Bohr magneton, $k$ is the Boltzmann constant, $T$ is the absolute temperature (in Kelvin), $\Theta$ is the Curie-Weiss constant (in Kelvin), and $g_{\mathrm{J}}$ is the Landé factor. The effective magnetic moment $\mu_{\text {eff }}$ (in Bohr magneton) can be calculated as follows:

$$
\mu_{\mathrm{eff}}=\left(\frac{3 k}{N_{\mathrm{A}} \mu_{B}^{2}}\right)^{1 / 2}(\chi \cdot T)^{1 / 2}=2.828(\chi \cdot T)^{1 / 2}
$$

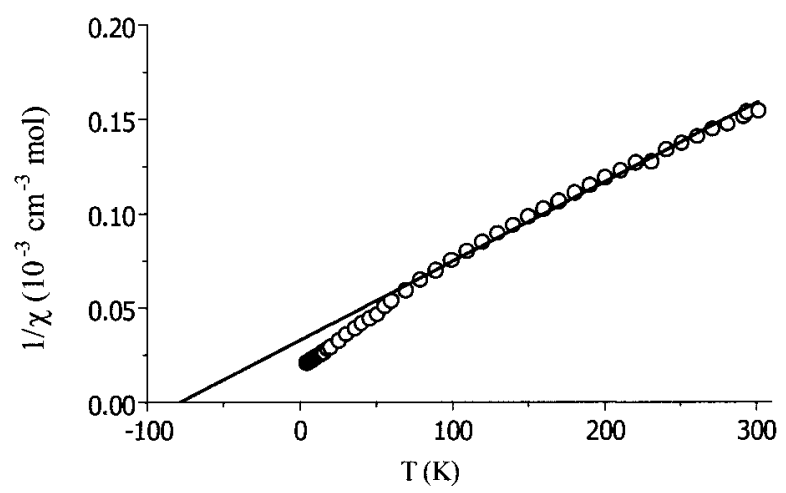

Figure 3. Inverse magnetic susceptibility of the liquid-crystalline Nd(III) complex $\left[\mathrm{Nd}\left(\mathrm{L}^{22} \mathrm{H}\right)_{3}\left(\mathrm{NO}_{3}\right)_{3}\right]$ (39) in the temperature range of 4-300 K. The solid line is obtained via a Curie-Weiss fit.

The magnetic susceptibilities of powdered samples were measured between 4.2 and $300 \mathrm{~K}$ on the mesomorphic complexes 38-42. The complexes follow the usual Curie-Weiss behavior of the magnetic susceptibility. The typical temperature dependence of the inverse magnetic susceptibility of the $\mathrm{Nd}$ (III) complex 39 at low temperatures is shown in Figure 3. The molar susceptibilities and the room-temperature effective magnetic moments of the rare-earth complexes are displayed in the Supporting Information. The experimental high-temperature limits of $\mu_{\text {eff }}$ of the two metal complexes are in good agreement with the expected theoretical values for the free-ion approximation. ${ }^{17}$

The magnetic birefringence of the rare-earth complexes 3842 in $\mathrm{CCl}_{4}$ solution was measured to study the behavior of these metal complexes in magnetic fields. Especially the magnetic birefringence can be used to determine the sign of the magnetic anisotropy $\Delta \chi$. In the experiment, the dependence of $\Delta R$ on the squared magnetic field strength is determined. $\Delta R$ is the difference between the molar refractions of the ordinary and extraordinary rays:

$$
\Delta R=\frac{6 n\left(n_{0}-n_{\mathrm{e}}\right)}{C\left(n^{2}+2\right)^{2}}
$$

$n_{0}, n_{\mathrm{e}}$, and $n$ being the refraction indices of the ordinary and extraordinary ray and their mean value, respectively. $C$ is the concentration (in $\mathrm{mol} \mathrm{L}^{-1}$ ). The molar constant of the magnetic birefringence ${ }_{\mathrm{m}} S$ is defined as $\Delta R / H^{2}$. The limiting value of $\mathrm{m}_{\mathrm{m}} S$ for the magnetic field strength approaching zero is proportional to the anisotropy of the molecular electronic polarizability $\Delta \alpha$ and to the anisotropy of the magnetic susceptibility $\Delta \chi$ :

$$
{ }_{\mathrm{m}} S=\frac{\Delta R}{H^{2}} \approx \frac{4 \pi N_{\mathrm{A}}}{45 k T} \cdot \Delta \chi \cdot \Delta \alpha \quad(H \rightarrow 0)
$$

The electronic polarizability anisotropy is determined by the ligand part of the metal complex only. The anisotropy of the magnetic susceptibility depends on the central metal ion. The values of $\Delta \alpha$ and $\Delta \chi$ calculated by the additive method are $\Delta \alpha$ $=21 \times 10^{-24} \mathrm{~cm}^{-3} \mathrm{~mol}^{-1}$ and $\Delta \chi=17 \times 10^{-29} \mathrm{~cm}^{-3} \mathrm{~mol}^{-1} .18$ The magnetic anisotropy of the rare-earth ions is about $1-2$ orders of magnitude larger than the magnetic anisotropy of the ligands. The molar constants of the magnetic birefringence,

(17) Siddall, J. H., III In Theory and Applications of Molecular Paramagnetism; Boudreaux, E. A., Mulay, L. N., Eds.; Interscience: New York, 1976; p 257.

(18) (a) Vul'fson, S. G.; Chevela, V. V.; Salnikov, Yu. I.; Vereschgin, A. N. Bull. Acad. Sci. USSR, Div. Chem. Sci. 1990, 39, 38. (b) Vul'fson, S. G. Molecular Magnetochemistry; Gordon and Breach: Amsterdam, 1998. 
Table 3. Magnetic Properties of Ligand $\mathrm{L}^{22} \mathrm{H}$ and of the Rare-Earth Complexes $\left[\mathrm{Ln}\left(\mathrm{L}^{22} \mathrm{H}\right)_{3}\left(\mathrm{NO}_{3}\right)_{3}\right](\mathbf{3 8}-\mathbf{4 2})$

\begin{tabular}{|c|c|c|c|c|c|c|c|c|c|}
\hline \multirow[b]{2}{*}{ compd } & \multicolumn{2}{|c|}{$\mu_{\mathrm{eff}^{a}}$} & \multirow[b]{2}{*}{$\Theta(\mathrm{K})$} & \multirow[b]{2}{*}{$\chi_{\text {iso }}^{b}$} & \multirow[b]{2}{*}{$\chi_{\text {or }}$} & \multirow[b]{2}{*}{$\chi_{\text {or }}-\chi_{\text {iso }}$} & \multirow[b]{2}{*}{$\Delta \chi_{\exp }^{c}$} & \multicolumn{2}{|c|}{${ }_{\mathrm{m}} S^{d}\left(\mathrm{~cm}^{3} \mathrm{~mol}^{-1}\right)$} \\
\hline & $\exp$ & theor & & & & & & $\exp$ & theor \\
\hline $\mathrm{L}^{22} \mathrm{H}$ & & & & -400 & -400 & $\sim 0$ & $\sim 0$ & $5.1 \times 10^{-15}$ & $4.9 \times 10^{-15}$ \\
\hline $38(\operatorname{Pr})$ & 3.60 & 3.58 & -78.2 & 3850 & 4160 & 310 & -930 & $-4.5 \times 10^{-9}$ & $-5.5 \times 10^{-13}$ \\
\hline $39(\mathrm{Nd})$ & 3.55 & 3.62 & -54.7 & 3750 & 4020 & 270 & -810 & $-4.1 \times 10^{-9}$ & $-3.8 \times 10^{-13}$ \\
\hline $40(\mathrm{Gd})$ & 7.8 & 7.9 & $\sim 0$ & 18200 & 18200 & $\sim 0$ & $\sim 0$ & $1.3 \times 10^{-10}$ & $1.4 \times 10^{-14}$ \\
\hline $41(\mathrm{~Tb})$ & 9.65 & 9.7 & -3.5 & 27980 & 29830 & 1850 & -5550 & $-3.1 \times 10^{-8}$ & $-3.4 \times 10^{-12}$ \\
\hline $42(\mathrm{Er})$ & 9.55 & 9.6 & -2.0 & 27270 & 28345 & 1075 & 1610 & $9.4 \times 10^{-9}$ & $1.3 \times 10^{-12}$ \\
\hline
\end{tabular}

${ }^{a}$ The effective magnetic moments $\mu_{\text {eff }}$ are expressed in Bohr magnetons $\left(\mu_{\mathrm{B}}\right)$ and were measured at room temperature. ${ }^{b}$ All magnetic susceptibility values $\chi$ are expressed in $10^{-6} \mathrm{~cm}^{3} \mathrm{~mol}^{-1}$ at the melting point. ${ }^{c}$ The calculation of the $\Delta \chi_{\text {exp }}$ values from the $\left(\chi_{\text {or }}-\chi_{\text {iso }}\right)$ values is discussed in the text. ${ }^{d}$ The molar constants of the magnetic birefringence ${ }_{\mathrm{m}} S=\Delta R / H^{2}$ are approximated to zero field.

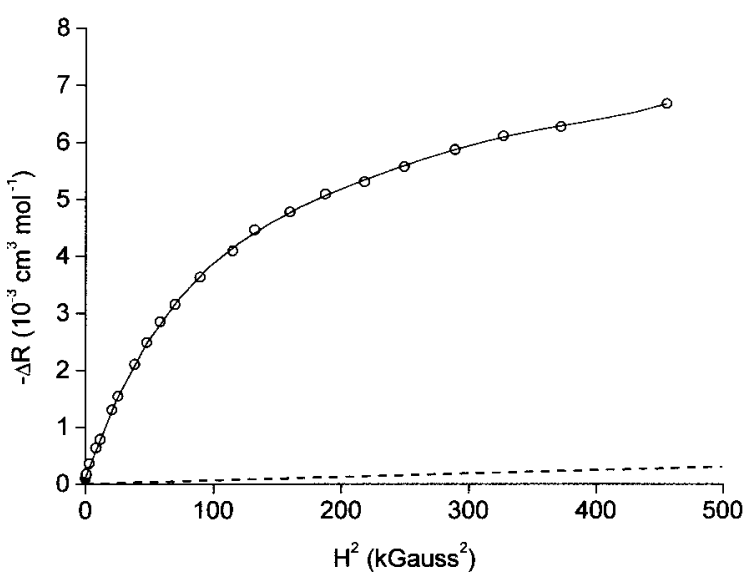

Figure 4. Dependence of the magnetic birefringence $(\Delta R)$ on the squared magnetic field strength $\left(H^{2}\right)$ of the liquid-crystalline $\operatorname{Pr}(\mathrm{III})$ complex $\left[\operatorname{Pr}\left(\mathrm{L}^{22} \mathrm{H}\right)_{3}\left(\mathrm{NO}_{3}\right)_{3}\right](\mathbf{3 8})$. The dotted line is the theoretical curve calculated by eq 4 .

calculated theoretically by eq 4 , and the experimental values extrapolated to zero magnetic field are presented in Table 3. The dependence of the magnetic birefringence $(\Delta R)$ on the magnetic field strength $\left(H^{2}\right)$ obtained for the $\operatorname{Pr}(\mathrm{III})$ complex 38 is presented in Figure 4, the theoretical curve being given by a dotted line. This theoretical curve represents the behavior of a single molecule in a magnetic field, and the curve is a straight line. Figure 4 shows the huge increase in the CottonMouton effect ( 3 to 4 orders of magnitude higher than the calculated value), even in weak fields $(<100 \mathrm{G})$. A deviation toward the $X$-axis for strong magnetic field strengths is observed for the experimental curve, indicating a saturation effect. This was previously observed for metal-free lyotropic liquid crystals, for colloids, and for biological macromolecules, and was related to particle association (Majorane effect) ${ }^{19}$ According to the ${ }_{\mathrm{m}} S_{\text {theor }}$ to ${ }_{\mathrm{m}} S_{\text {exp }}$ ratio, the metal complexes are associated forming oriented domains, and each of these domains contains more than $10^{4}$ molecules of the metal complexes. The strong CottonMouton effect is caused by the high values of the magnetic anisotropy of the metal ion, the electronic polarization of the ligand, and the association of the metal complexes in solution. The magnetic birefringence of the $\operatorname{Er}(\mathrm{III})$ complex has a positive sign, in agreement with model calculations $(\Delta \alpha>0, \Delta \chi>0)$. In this case, the maximum component of the electronic polarizability tensor coincides with the direction of the long molecular axis. For the $\operatorname{Pr}(\mathrm{III}), \mathrm{Nd}(\mathrm{III})$, and $\mathrm{Tb}(\mathrm{III})$ complexes, the magnetic birefringence is negative (as in the case of Dy(III) complexes). This indicates a negative magnetic anisotropy $(\Delta \alpha>0, \Delta \chi<0)$. In other words, in an axial approximation,

(19) Maret, G.; Dransfeld, K. In Strong and Ultrastrong Magnetic Fields and Their Applications; Herlach, F., Ed.; Springer-Verlag: Berlin, 1985; p 80 .

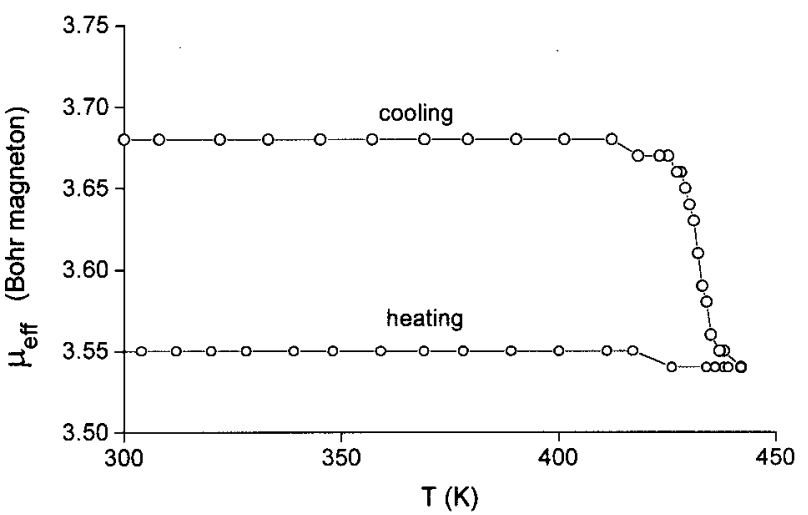

Figure 5. Effective magnetic moments $\mu_{\text {eff }}$ of the liquid-crystalline $\operatorname{Pr}(\mathrm{III})$ complex $\left[\mathrm{Pr}\left(\mathrm{L}^{22} \mathrm{H}\right)_{3}\left(\mathrm{NO}_{3}\right)_{3}\right](38)$ in the temperature range of $300-442 \mathrm{~K}$.

the maximum component of the magnetic susceptibility tensor is perpendicular to the long molecular axis. For the Gd(III) complex, the magnetic birefringence has a very small positive value.

To obtain quantitative information on the degree of magnetic anisotropy of the mesogenic complexes 38-42, we carried out magnetic susceptibility measurements in the mesophase. Alignment of the samples in a static magnetic field (field strength $12000 \mathrm{G}$ ) was observed. The samples exhibited a Curie-Weiss behavior for the temperature dependence of their magnetic properties, when heated from the solid state through the SmA phase until the isotropic phase was reached. When the samples were cooled from the isotropic phase to the mesophase (in the presence of a magnetic field), in the vicinity of the clearing point a drastic increase in the magnetic moment $\mu_{\mathrm{eff}}$ was observed in comparison to the initial values recorded by heating of the samples. The increase takes place over a narrow temperature range, and upon further cooling, the magnetic properties vary according to the Curie-Weiss law, but with a different higher $\mu_{\text {eff }}$ than in the heating cycle. This behavior can be referred to as a magnetic-field-induced orientation in the liquid-crystalline phase of a magnetically anisotropic sample with its axis of maximum magnetic susceptibility parallel to the magnetic field. The orientation of these molecular magnetic materials in the mesophase can be observed by cooling from the isotropic phase rather than by heating the solid sample, because of the high viscosity of the SmA phase. The oriented mesophase can be frozen into a glassy state. During the second heating run, the same values for $\chi$ are measured as in the first cooling run. The temperature dependence of the magnetic moments of the mesogenic $\operatorname{Pr}(\mathrm{III})$ complex 38 in the temperature range from 300 to $410 \mathrm{~K}$ (heating and cooling) is shown in Figure 5.

In the case of a powdered solid sample (i.e. beneath the melting temperature of the complex), the measured magnetic 
susceptibility is equal to $\chi_{\text {iso }}$ (isotropic magnetic susceptibility). Also in the isotropic phase, the isotropic magnetic susceptibility $\chi_{\text {iso }}$ is measured. $\chi_{\text {iso }}$ is increasing with increasing temperature. The magnetic susceptibility $\chi_{\text {or }}$ measured in the mesophase is equal to (or less than, if alignment is not complete) the greater of the two components $\chi_{\perp}$ or $\chi_{\|} \cdot \chi_{\text {or }}$ corresponds to the maximum of the $\chi$-tensor. The actual value of the experimental magnetic anisotropy $\Delta \chi_{\text {exp }}$ depends on the relative values of $\chi_{\perp}$ or $\chi_{\| 1}$, or to say it in other words, on the sign of $\Delta \chi_{\text {exp }}$ :

$$
\begin{gathered}
\Delta \chi_{\text {exp }}=\frac{3}{2}\left(\chi_{\text {or }}-\chi_{\text {iso }}\right) \quad \text { if } \chi_{\|}>\chi_{\perp} \\
\Delta \chi_{\exp }=-3\left(\chi_{\text {or }}-\chi_{\text {iso }}\right) \quad \text { if } \chi_{\|}<\chi_{\perp}
\end{gathered}
$$

The sign of $\Delta \chi_{\text {exp }}$ can be determined from EPR and from magnetic birefringence measurements. If $\Delta \chi=\chi_{\|}-\chi_{\perp}<0$, or $\chi_{\|}<\chi_{\perp}$, the molecular long axis is oriented perpendicular to the direction of the magnetic field, and in the oriented mesophase, $\chi_{\perp}$ will be measured. If $\Delta \chi=\chi_{\|}-\chi_{\perp}>0$, or $\chi_{\|}>$ $\chi_{\perp}$, the molecular long axis is oriented parallel to the direction of the magnetic field, and in the oriented mesophase, $\chi_{\|}$will be measured. Therefore, we can calculate the magnitude of $\Delta \chi_{\exp }$ in the $\operatorname{Pr}(\mathrm{III}), \mathrm{Nd}(\mathrm{III})$, and $\mathrm{Tb}$ (III) compounds, including the orientational behavior, using information of the EPR and magnetic birefringence measurements about the negative sign of $\Delta \chi=\chi_{\|}-\chi_{\perp}$. For the $\operatorname{Er}(\mathrm{III})$ compound, we can propose a positive sign of $\Delta \chi=\chi_{\|}-\chi_{\perp}$ on the basis of EPR and magnetic birefringence measurements. The experimental data for $\chi_{\text {or }}$ and $\chi_{\text {iso }}$ at the phase transition temperatures and the estimated values for $\Delta \chi_{\exp }$ can be found in Table 3 . As a result after a heating and a cooling cycle in a magnetic field, we obtained a magnetically anisotropic molecular material. This anisotropy is obvious from the cosine-like angle dependence of the magnetic susceptibility, measured on aligned rare-earth compounds in the glassy state as a function of the $\alpha$ angle between the directions of the predominant orientation and the magnetic field.

EPR Measurements. The mesogenic $\mathrm{Tb}(\mathrm{III})$ and $\mathrm{Er}(\mathrm{III})$ complexes $\mathbf{4 1}$ and $\mathbf{4 2}$ were studied by electron paramagnetic resonance (EPR). In the past, only EPR spectra of Gd(III)containing metallomesogens were studied. ${ }^{20}$ The spin lattice relaxation time of $\mathrm{Tb}$ (III) and $\mathrm{Er}$ (III) is much shorter than that of $\mathrm{Gd}(\mathrm{III})$, so that EPR spectra of $\mathrm{Tb}(\mathrm{III})$ and $\mathrm{Er}(\mathrm{III})$ compounds can only be detected at liquid-helium temperature and not in the mesophase (above $+100{ }^{\circ} \mathrm{C}$ ). Gd(III) is the only trivalent lanthanide ion with an observable EPR signal at room temperature (or at higher temperatures). ${ }^{21}$ To avoid this obstacle, we used Gd(III) complex $\mathbf{4 0}$ as a spin probe to study the orientational behavior of the mesomorphic $\mathrm{Tb}$ (III) and $\mathrm{Er}$ (III) complexes in a magnetic field. The Gd(III) complex itself cannot be oriented very easily in a magnetic field, because of the ${ }^{8} \mathrm{~S}_{7 / 2}$ ground state. The Q-band EPR spectrum of Gd(III) reflects this orientational behavior. The EPR spectra of Gd(III) mixed in small amount (5 wt \%) with the $\mathrm{Tb}(\mathrm{III})$ or $\operatorname{Er}(\mathrm{III})$ compound are given in Figures 6 and 7, and alignment of the samples is obvious from the different features in the EPR spectra at different orientations. As a control experiment, the samples were cooled in the absence of an external magnetic field: no alignment occurred and the EPR spectra at different orientations proved to be identical.

(20) Bikchantaev, I.; Galyametdinov, Yu.; Kharitonova, O.; Ovchinnikov, IV; Bruce, D. W.; Dunmur, D. A.; Guillon, D.; Heinrich, B. Liq. Cryst. 1996, 20, 489.

(21) Stephens, E. M. Gadolinium as an EPR probe. In Lanthanide Probes in Life, Chemical and Earth Sciences, Theory and Practice; Bünzli, J. C. G., Choppin, G. R., Eds.; Elsevier: Amsterdam, 1989; Chapter 6, p 181.

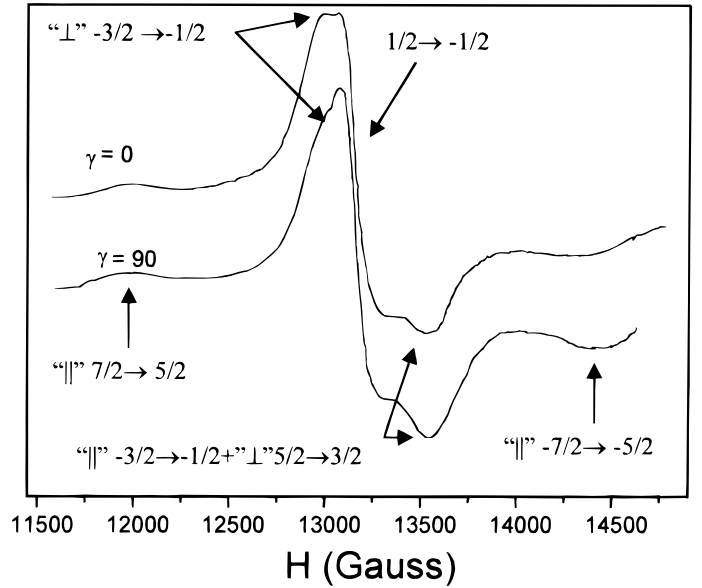

Figure 6. The experimental EPR spectra of the Gd(III) complex in the smectic A mesophase of the Tb(III)-containing host matrix. $\gamma$ is the angle between the magnetic field and the direction of initial alignment of the sample.

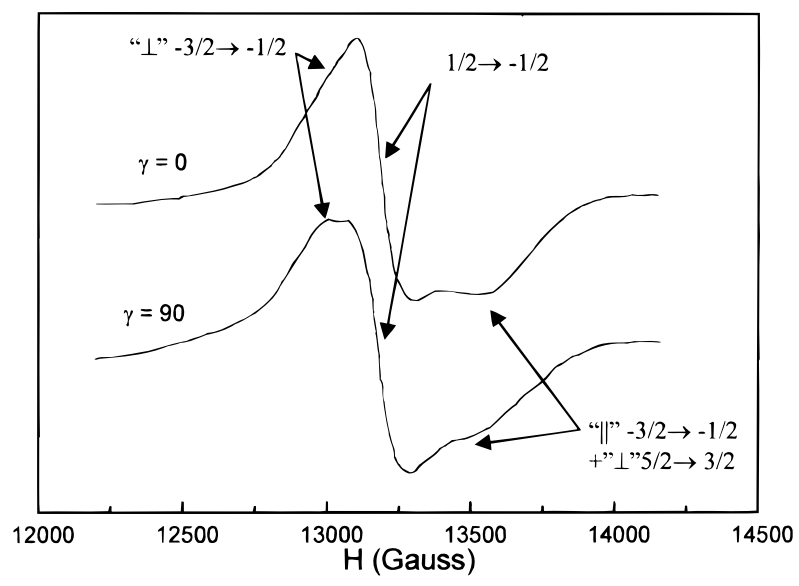

Figure 7. The experimental EPR spectra of the Gd(III) complex in the smectic A mesophase of the $\operatorname{Er}(\mathrm{III})$-containing host matrix. $\gamma$ is the angle between the magnetic field and the direction of initial alignment of the sample.

The positions of the EPR lines of the Gd(III) complex can be calculated by use of the spin-Hamiltonian: ${ }^{22}$

$$
H=g \beta \mathbf{H} \cdot \mathbf{S}+\sum_{k, g} B_{k}^{q} O_{k}^{q}
$$

where $\beta$ is the Bohr magneton, $\mathbf{H}$ the magnetic field strength, $\mathbf{S}$ the electron spin, and $g$ the $g$-factor. The $O_{k}^{q}$ are spin-operators with coefficients $B_{k}{ }^{q}$. The number of $(k, q)$ combinations depends on the symmetry of the crystal field around the $\mathrm{Gd}(\mathrm{III})$ ion, and $k=2,4$, or 6 and $0 \leq q \leq k$. The contribution of the Zeeman term in the spin-Hamiltonian is much greater than the contribution of the ligand-field part. In the smectic mesophase of both $\mathrm{Tb}(\mathrm{III})$ - and $\mathrm{Er}(\mathrm{III})$-containing liquid crystals, we observed a typical "powder-type" EPR spectrum with a fine structure, consisting of two sets of EPR peaks with "parallel" and "perpendicular" features. The former may be assigned to the symmetry axis of the crystal field, the latter to the plane perpendicular to this axis. The positions of the EPR lines of the Gd(III) complex were interpreted by a spin-Hamiltonian with effective electron spin $S=7 / 2$ and assuming a crystal-field

(22) Abragam, A.; Bleaney, B. Electron Paramagnetic Resonance of Transition Ions; Clarendon Press: Oxford, 1970. 
symmetry $C_{3 h}$, as in $\operatorname{Gd}(\mathrm{III})$ ethyl sulfate. ${ }^{23}$ The spin-Hamiltonian parameters are $g \approx 1.98, B_{2}{ }^{0} \approx 60 \times 10^{-4} \mathrm{~cm}^{-1} \cdot B_{4}{ }^{0}, B_{4}{ }^{3}$, $B_{6}{ }^{0}$, and $B_{6}{ }^{3}$ are too small to be determined from such insufficiently resolved EPR data. This set of parameters implies that the crystal field is practically axially symmetric, the mean orientation of this axis corresponding to the mesophase director. ${ }^{20}$ The intensity of each ("parallel" or "perpendicular") peak may be roughly considered as proportional to the number of molecules directed along the external magnetic field with the molecular axis assigned to this peak. From the relative intensities of the different kinds of peaks, one can conclude which molecular axis (long or short axis) is predominantly directed along the magnetic field at a given orientation of the sample. The most obvious and convenient way to examine the orientation in a magnetic field is to compare the " $\perp$ " $-3 / 2 \rightarrow-1 / 2$ peak with the $1 / 2 \rightarrow-1 / 2$ one (marked in Figures 6 and 7). From a theoretical point of view, the intensity of the central $1 / 2 \rightarrow-1 / 2$ peak must be constant for different orientations of the sample, because in a first approximation this transition is isotropic in nature. This ensures that any changes in the intensity of the " $\perp$ " $-3 / 2 \rightarrow-1 / 2$ peak relative to the $1 / 2 \rightarrow-1 / 2$ peak can be considered as reflecting the orientational behavior of the molecules in a magnetic field. When $\gamma$ varies from 0 to $90^{\circ}$, the intensity of the " $\perp$ " $-3 / 2 \rightarrow-1 / 2$ peak appreciably falls down relative to the $1 / 2 \rightarrow-1 / 2$ peak for the $\mathrm{Tb}(\mathrm{III})$ compound, whereas the intensity increases for the $\mathrm{Er}$ (III) compound, proving unambiguously that the molecular alignments of the $\mathrm{Tb}$ (III) and Er(III) compounds are opposite. The " $\perp$ " $-3 / 2 \rightarrow-1 / 2$ peak is associated with a plane perpendicular to the $C_{3}$-axis of the crystal field (long molecular axis). The intensity of this transition may be considered as proportional to the number of molecules aligned with the long axis perpendicular to the external magnetic field at any particular orientation of the sample. Since the intensity of " $\perp$ " $-3 / 2 \rightarrow-1 / 2$ peak at the initial orientation of the sample (the sample was aligned upon cooling in a magnetic field; $\gamma=0^{\circ}$ ) is maximal for the $\mathrm{Tb}$ (III) compound, we can conclude that the $\mathrm{Tb}(\mathrm{III})$ complexes tend to orient perpendicularly to the magnetic field. The opposite conclusion follows for the Er(III) complex. The magnetic anisotropy of mesophase is positive for $\mathrm{Er}(\mathrm{III})$ and negative for $\mathrm{Tb}$ (III)-containing liquid crystals. The angular dependence of the other peaks in the EPR spectra confirms these conclusions.

\section{Discussion}

Previously, the stoichiometry of the metal complexes was claimed as $\left[\mathrm{LnL}(\mathrm{LH})_{2}\left(\mathrm{NO}_{3}\right)_{2}\right]^{7}$ with a metal:ligand ratio of $1: 3$, but with only one of the Schiff base ligands deprotonated. In this study, we show that the stoichiometry should be reformulated as $\left[\mathrm{Ln}(\mathrm{LH})_{3}\left(\mathrm{NO}_{3}\right)_{3}\right]$, with the Schiff base ligands in a zwitterionic form and coordinating to the metal ion via the negatively charged phenolic oxygen only. The three nitrate groups coordinate in a bidentate fashion. The coordination number of the lanthanide ion is nine, and the coordination polyhedron can be described as a distorted monocapped square antiprism. Spectroscopic and molecular modeling data indicate that the first coordination sphere around the lanthanide ion is not changed by elongation of the alkyl chains. The Schiff base complexes have the advantage of being much easier to synthesize than other rare-earth-containing compounds which could be the starting point of mesomorphic materials, such as complexes of 2,6-bis(benzimidazol-2'-yl)pyridines. ${ }^{24}$

(23) Low, W. Paramagnetic Resonance in Solids; Academic Press: New York, 1960.

(24) Nozary, H.; Piguet, C.; Tissot, P.; Bernardinelli, G.; Bünzli, J. C. G.; Deschenaux, R.; Guillon, D. J. Am. Chem. 1998, 120, 12274.
An interesting feature of the liquid-crystalline rare-earth complexes (SmA phase) is their ability to be oriented in the mesophase by an applied magnetic field, due to their large magnetic anisotropy. The sign of magnetic anisotropy $\Delta \chi$ depends on the choice of the rare-earth ion and this sign determines whether the metal complexes orient with the director parallel to the magnetic field $(\Delta \chi>0)$ or perpendicular to the magnetic field $(\Delta \chi<0)$. Although the value of $\Delta \chi$ depends on the crystal-field perturbation of the rare-earth ion, the sign of $\Delta \chi$ is a function of the electronic angular momenta of the rareearth ion, and is constant for a given rare-earth ion. ${ }^{25} \mathrm{~A}$ positive magnetic anisotropy $(\Delta \chi>0)$ is expected for $\operatorname{Eu}(\mathrm{III}), \operatorname{Er}(\mathrm{III})$, $\mathrm{Tm}(\mathrm{III})$, and $\mathrm{Yb}(\mathrm{III})$, and a negative magnetic anisotropy $(\Delta \chi$ < 0) for $\mathrm{Pr}(\mathrm{III}), \mathrm{Nd}(\mathrm{III}), \mathrm{Tb}(\mathrm{III}), \mathrm{Ho}(\mathrm{III})$, and $\mathrm{Dy}(\mathrm{III})$. No measurable magnetic anisotropy is expected for $\mathrm{La}(\mathrm{III}), \mathrm{Gd}(\mathrm{III})$, and Lu(III) ions (except from diamagnetic contributions of the ligands), and a small positive anisotropy for Sm(III). These predictions were experimentally proved in this study for Pr(III), Nd(III), Gd(III), Tb(III), and Er(III) complexes. The orientational behavior of the rare-earth ions is in contrast to what is observed for other paramagnetic metallomesogens. All vanadyl-containing metallomesogens orient with the director parallel to the magnetic field $(\Delta \chi>0)$. The orientational behavior of the copper(II) complexes depends on the number of aromatic rings present in the complex ( 4 or 6 ): $\Delta \chi>0$ for 6-ring systems. For 4-ring systems the situation is more complicated: $\Delta \chi>0$ or $\Delta \chi<0$ depending on the molecular structure. For the rare-earth complexes the orientational behavior is determined by the paramagnetic contribution of the metal ion to $\Delta \chi$ only, because this contribution is much larger than the diamagnetic contributions of the aromatic rings in the complex.

\section{Conclusions}

In this paper, we described rare-earth-containing metallomesogens with 4-alkoxy- $N$-alkyl-2-hydroxybenzaldimine Schiff bases as ligand. The ligands are not liquid crystals themselves, but complex formation with rare-earth nitrates induced mesomorphism. All the complexes (except those with very short alkyl chains) display a viscous smectic A phase. It was shown the rare-earth complexes have the composition $\left[\mathrm{Ln}(\mathrm{LH})_{3}\left(\mathrm{NO}_{3}\right)_{3}\right]$, with the Schiff base ligands in a zwitterionic form. Due to their large magnetic anisotropy, the paramagnetic liquid crystals can be aligned in an external magnetic field. Depending on the choice of the rare-earth ion, the complexes will align with their long molecular axis either parallel or perpendicular to the magnetic field. Therefore, the direction of orientation can be changed simply by replacing the rare-earth ion by another one, without the need for modifying the ligands themselves. Although we demonstrated the possibility of magnetic alignment, the actual switching rate is slow, because of the high viscosity of the complexes. A next step is to try to reduce the viscosity and to lower the transition temperatures without altering the thermal stability too much. The high viscosity is not only a disadvantage, because the mesophase can be supercooled to a glassy mesophase, forming an anisotropic glass. When the glass formation is carried out in a magnetic field, anisotropic magnetic materials are obtained.

\section{Experimental Section}

Techniques. ${ }^{1} \mathrm{H}$ NMR spectra were obtained on a Bruker AMX400 spectrometer $(400 \mathrm{MHz})$, a Bruker WM-250 spectrometer (250 $\mathrm{MHz}$ ), or on a Varian UNITY-300 spectrometer (300 MHz) using

(25) Bleaney, B. J. Magn. Reson. 1972, 8, 91. 
$\mathrm{CDCl}_{3}$ as solvent and tetramethylsilane (TMS) as internal standard. ${ }^{13} \mathrm{C}$ NMR solution spectra were measured on Varian UNITY-300 spectrometer $(75.43 \mathrm{MHz}) .{ }^{13} \mathrm{C}$ CP/MAS NMR spectra $(75.43 \mathrm{MHz})$ in the solid phase were obtained on a Varian UNITY-300 spectrometer, with a Doty Scientific probe. The samples were contained in $7 \mathrm{~mm}$ diameter zirconia or silicium nitride rotors with Kel-F end caps. Spinning rates were between 2 and $3 \mathrm{kHz}$. Chemical shifts were measured relative to adamantane as external standard. IR spectra were recorded on a Perkin-Elmer 580B spectrometer with the sample pressed in a $\mathrm{KBr}$-pellet technique, mixed with vaseline to a mull, or dissolved in $\mathrm{CCl}_{4}$. Elemental analyses $(\mathrm{CHN})$ were obtained on a CE-Instrument EA-1110 elemental analyzer. Differential scanning calorimetry (DSC) measurements were carried out on a Mettler-Toledo DSC821e module (scan rate of $10{ }^{\circ} \mathrm{C} \mathrm{min}^{-1}$ under a nitrogen flow). Optical textures of the mesophases were observed with an Olympus BX60 polarizing microscope equipped with a LINKAM TMS600 hot stage and a LINKAM TMS93 programmable temperature-controller. Thermogravimetric analysis was done with a Polymer Laboratories STA1000H TGDTA apparatus, using a static air atmosphere. The temperature dependence of the magnetic susceptibilities in the range $4.2-300 \mathrm{~K}$ of the powdered metallomesogens were recorded using a Faraday type magnetometer. Data collection was done via a PC-controlled Cahn D-200 microbalance and a Bruker B-MN 200/60 power supply. ${ }^{26}$ The applied magnetic field had a strength of $12000 \mathrm{G}$. The magnetic susceptibilities of the compounds in the temperature range 300-500 $\mathrm{K}$ were obtained using a home-built apparatus..$^{27}$ The molar susceptibilities were corrected for the underlying diamagnetism applying Pascal's scheme. ${ }^{28}$ The $\chi(T)$ fits were done with computer programs developed in Darmstadt. The magnetic birefringence was measured on a previously described setup. ${ }^{29}$ The magnetic field strength ranged between 0 and $20000 \mathrm{G}$, and the magnetic field was applied perpendicularly to the laser beam. A He$-\mathrm{Ne}$ laser $(\lambda=632.8 \mathrm{~nm})$ was used as the light source. The EPR experiments were performed on a Q-band EPR spectrometer RE-1308 (34 GHz), with an external magnetic field strength of 14000 $\mathrm{G}$, and with a temperature controller capable of stabilizing the temperature within less than $0.2 \mathrm{~K}$. Alignment was achieved by slow cooling of the sample from the isotropic to smectic A phase in the magnetic field. A copper-constantan thermocouple inserted into a sample tube and positioned just above the sample surface was used for temperature measurements. Organic reagents were obtained from ACROS, Aldrich, Sigma, or Fluka. Hydrated rare earth nitrates were purchased from Aldrich. The molecular modeling calculations were performed using HyperChem 5.02 for Windows 95/NT (force field $\mathrm{MM}^{+}$).

Synthesis. (a) Preparation of 5-Ethoxy-2-[(octadecylimino)methyl]phenol, $\mathbf{L}^{3} \mathbf{H}$. 2,4-Dihydroxybenzaldehyde (50 mmol, $6.91 \mathrm{~g}$ ) was dissolved in ethanol $(100 \mathrm{~mL})$. To the solution was added $\mathrm{KOH}(50$ $\mathrm{mmol}, 2.81 \mathrm{~g}$ ) and iodoethane $(50 \mathrm{mmol}, 7.80 \mathrm{~g})$. The mixture was heated for $15 \mathrm{~h}$ at $60{ }^{\circ} \mathrm{C}$ (oil bath) with stirring, in a nitrogen atmosphere. After the reaction the dark brown reaction mixture was left to cool to room temperature, water $(200 \mathrm{~mL})$ was added, and 4-ethoxy-2-benzaldehyde was removed from the reaction mixture by steam distillation. The milky emulsion of the aldehyde in water $(2 \mathrm{~L})$ was extracted by diethyl ether $(4 \times 200 \mathrm{~mL})$. The combined organic layers were dried by anhydrous $\mathrm{MgSO}_{4}$ and the solvent was removed on a water bath using a rotavap at ambient pressure. 4-Ethoxy-2hydroxybenzaldehyde was obtained as a yellow oil, which crystallized to a beige solid by leaving the oil overnight in a freezer. Yield: 3.87 $\mathrm{g}(47 \%) .{ }^{1} \mathrm{H} \mathrm{NMR}\left(\delta \mathrm{ppm}, \mathrm{CDCl}_{3}, 250 \mathrm{MHz}\right): 1.43\left(\mathrm{t}, 3 \mathrm{H}, \mathrm{CH}_{3}\right), 4.08$ (quart, $\left.2 \mathrm{H}, \mathrm{CH}_{2} \mathrm{O}\right), 6.40\left(\mathrm{~d}, 1 \mathrm{H}, \mathrm{H}\right.$-aryl, $\left.J_{\mathrm{m}}=2.3 \mathrm{~Hz}\right), 6.52(\mathrm{dd}, 1 \mathrm{H}$, $\mathrm{H}$-aryl, $\left.J_{\mathrm{o}}=8.6 \mathrm{~Hz}, J_{\mathrm{m}}=2.3 \mathrm{~Hz}\right), 7.42\left(\mathrm{~d}, 1 \mathrm{H}, \mathrm{H}\right.$-aryl, $\left.J_{\mathrm{o}}=8.5 \mathrm{~Hz}\right)$, $9.70(\mathrm{~s}, 1 \mathrm{H}, \mathrm{CH}=\mathrm{O}), 11.45(\mathrm{~s}, 1 \mathrm{H}, \mathrm{OH})$.

4-Ethoxy-2-hydroxybenzaldehyde (3.85 g, $23.2 \mathrm{mmol})$ and octadecylamine $(6.24 \mathrm{~g}, 23.2 \mathrm{mmol})$ were dissolved in absolute ethanol (200

(26) Gehring, S.; Fleischhauer, P.; Paulus, H.; Haase, W. Inorg. Chem. $1993,32,54$.

(27) Merz, L.; Haase, W. J. Chem. Soc., Dalton Trans. 1980, 875.

(28) Weiss, A.; Witte, H. Magnetochemie; Verlag Chemie: Weinheim, 1973.

(29) Abdullin, I. R.; Vul'sfon, S. G.; Kazakova, E. Kh Bull. Acad. Sci. USSR, Div. Chem. Sci. 1987, 36, 2551.
$\mathrm{mL}$ ) and a few drops of glacial acetic acid were added as the catalyst. Immediately after mixing the reagents, the solution turned yellow. The mixture was heated during $3 \mathrm{~h}$ at reflux. The solution was left to cool to room temperature and the Schiff base precipitated. The crude Schiff base was recrystallized twice from absolute ethanol. The crystallization was completed in an ice bath. The yellow crystals were filtered on a Büchner funnel, washed with cold absolute ethanol, and dried in vacuo. Yield: $4.21 \mathrm{~g}(43 \%) .{ }^{1} \mathrm{H}$ NMR $\left(\delta, \mathrm{CDCl}_{3}, 250 \mathrm{MHz}\right): 0.88(\mathrm{t}, 3 \mathrm{H}$, $\left.\mathrm{CH}_{3}\right), 1.10-1.35\left(\mathrm{~m}, 30 \mathrm{H}, \mathrm{CH}_{2}\right), 1.38\left(\mathrm{t}, 3 \mathrm{H}, \mathrm{CH}_{3}\right), 1.67(\mathrm{~m}, 2 \mathrm{H}$, $\mathrm{NCH}_{2} \mathrm{CH}_{2}$ ), 3.50 (t, $2 \mathrm{H}, \mathrm{NCH}_{2}$ ), 4.04 (t, $2 \mathrm{H}, \mathrm{OCH}_{2}$ ), 6.30 (d, 1H, H-aryl, $\left.J_{\mathrm{m}}=2.4 \mathrm{~Hz}\right), 6.36\left(\mathrm{dd}, 1 \mathrm{H}, \mathrm{H}-\operatorname{aryl}, J_{\mathrm{o}}=8.5 \mathrm{~Hz}, J_{\mathrm{m}}=2.4 \mathrm{~Hz}\right), 7.05$ $\left(\mathrm{d}, 1 \mathrm{H}, \mathrm{H}\right.$-aryl, $\left.J_{\mathrm{o}}=8.5 \mathrm{~Hz}\right), 8.09(\mathrm{~s}, 1 \mathrm{H}, \mathrm{CH}=\mathrm{N}), 14.19(\mathrm{~s}, 1 \mathrm{H}, \mathrm{OH})$.

(b) Preparation of 2-[(Octadecylimino)methyl]-5-(octyloxy)phenol, $\mathbf{L}^{9} \mathbf{H}$. 4-Octyloxy-2-hydroxybenzaldehyde was prepared by refluxing for $3 \mathrm{~h} \mathrm{2,4-dihydroxybenzaldehyde} \mathrm{(50} \mathrm{mmol,} 6.91 \mathrm{~g}$ ) with 1-bromooctane (50 mmol, $9.66 \mathrm{~g}$ ) in DMF, with $\mathrm{KHCO}_{3}(50 \mathrm{mmol}$, $5.01 \mathrm{~g})$ as the base. After the reaction mixture was cooled to room temperature it was poured into an aqueous $\mathrm{HCl}$ solution $(6 \mathrm{~N})$. The organic layer was separated and the aqueous layer was extracted with diethyl ether. The combined organic layers were dried by anhydrous $\mathrm{MgSO}_{4}$ and the solvent was removed under reduced pressure. The crude aldehyde was purified on a silica column with $n$-heptane/ethyl acetate (90:10) as the eluent. Yield: $73 \%$ (9.14 g). ${ }^{1} \mathrm{H}$ NMR (400 MHz, $\mathrm{CDCl}_{3}$, $\delta$ ppm): $0.88\left(\mathrm{t}, 3 \mathrm{H}, \mathrm{CH}_{3}\right), 1.00-1.55\left(\mathrm{~m}, 10 \mathrm{H}, \mathrm{CH}_{2}\right), 1.79$ (quintet, $\left.2 \mathrm{H},-\mathrm{CH}_{2}-\mathrm{CH}_{2}-\mathrm{O}-\right), 4.00$ (t, $2 \mathrm{H},-\mathrm{CH}_{2}-\mathrm{O}-$ ), 6.40 (d, 1H, H-aryl), $6.52\left(\mathrm{dd}, 1 \mathrm{H}, \mathrm{H}\right.$-aryl), $7.41(\mathrm{~d}, 1 \mathrm{H}, \mathrm{H}$-aryl $), 9.70\left(\mathrm{~s}, 1 \mathrm{H}, \mathrm{CH}=\mathrm{O}, J_{\mathrm{o}}=\right.$ $\left.8.5 \mathrm{~Hz}, J_{\mathrm{m}}=2.5 \mathrm{~Hz}\right)$.

The Schiff base $\mathrm{L}^{9} \mathrm{H}$ was prepared by refluxing $9.14 \mathrm{~g}(36.5 \mathrm{mmol})$ of 4-octyloxy-2-hydroxybenzaldehyde with $9.84 \mathrm{~g}(36.5 \mathrm{mmol})$ of $n$-octadecylamine in absolute ethanol for $3 \mathrm{~h}$, with a few drops of glacial acetic acid as the catalyst. The crude product was crystallized several times from hot absolute ethanol. Yield 79\% (14.5 g). ${ }^{1} \mathrm{H}$ NMR (400 $\left.\mathrm{MHz}, \mathrm{CDCl}_{3}, \delta \mathrm{ppm}\right): 0.88\left(\mathrm{t}, 6 \mathrm{H}, \mathrm{CH}_{3}\right), 1.25-1.44\left(\mathrm{~m}, 40 \mathrm{H}, \mathrm{CH}_{2}\right)$, 1.67 (quintet, $2 \mathrm{H},-\mathrm{CH}_{2}-\mathrm{CH}_{2}-\mathrm{N}$ ), 1.77 (quintet, $2 \mathrm{H},-\mathrm{CH}_{2}-\mathrm{CH}_{2}-$ $\mathrm{O}-$ ), 3.50 (t, 2H, $-\mathrm{CH}_{2}-\mathrm{N}-$ ), 3.95 (t, 2H, $-\mathrm{CH}_{2}-\mathrm{O}-$ ), 6.30 (dd, $1 \mathrm{H}, \mathrm{H}$-aryl, $\left.J_{\mathrm{m}}=2.5 \mathrm{~Hz}\right), 6.34\left(\mathrm{~d}, 1 \mathrm{H}, \mathrm{H}\right.$-aryl, $J_{\mathrm{o}}=8.5 \mathrm{~Hz}, J_{\mathrm{m}}=2.5$ $\mathrm{Hz}), 7.04\left(\mathrm{~d}, 1 \mathrm{H}, \mathrm{H}\right.$-aryl, $\left.J_{\mathrm{o}}=8.5 \mathrm{~Hz}\right), 8.08(\mathrm{~s}, 1 \mathrm{H}, \mathrm{CH}=\mathrm{N}), 14.08(\mathrm{~s}$, $1 \mathrm{H}, \mathrm{OH})$

(c) Preparation of 2-[(Octadecylimino)methyl]-5-(tetradecyloxy)phenol (34), L ${ }^{15}$ H. 4-Tetradecyloxy-2-hydroxybenzaldehyde was prepared by refluxing for $3 \mathrm{~h}$ 2,4-dihydroxybenzaldehyde $(20.73 \mathrm{~g}, 0.15$ mol) with 1-bromotetradecane (41.59 g, $0.15 \mathrm{~mol})$ in DMF, with $\mathrm{KHCO}_{3}(15.04 \mathrm{~g}, 0.15 \mathrm{~mol})$ as the base. After the reaction mixture was cooled to room temperature it was poured into an aqueous $\mathrm{HCl}$ solution $(6 \mathrm{~N})$. The organic layer was separated and the aqueous layer was extracted with diethyl ether. The combined organic layers were dried by anhydrous $\mathrm{MgSO}_{4}$ and the solvent was removed under reduced pressure. The crude aldehyde was purified by crystallization from hot acetonitrile. Yield: $54 \%(27 \mathrm{~g}) .{ }^{1} \mathrm{H}$ NMR $\left(250 \mathrm{MHz}, \mathrm{CDCl}_{3}, \delta \mathrm{ppm}\right)$ : $0.90\left(\mathrm{t}, 3 \mathrm{H}, \mathrm{CH}_{3}\right), 1.0-1.6\left(\mathrm{~m}, 22 \mathrm{H}, \mathrm{CH}_{2}\right), 1.80$ (quintet, $2 \mathrm{H},-\mathrm{CH}_{2}-$ $\left.\mathrm{CH}_{2}-\mathrm{O}-\right), 4.00$ (t, $\left.2 \mathrm{H},-\mathrm{CH}_{2}-\mathrm{O}-\right), 6.40$ (d, $1 \mathrm{H}, \mathrm{H}$-aryl), 6.50 (dd, $1 \mathrm{H}, \mathrm{H}$-aryl), 7.40 (d, $1 \mathrm{H}, \mathrm{H}$-aryl), $9.70(\mathrm{~s}, 1 \mathrm{H}, \mathrm{CH}=\mathrm{O})$.

The Schiff base $\mathrm{L}^{15} \mathrm{H}$ was prepared by refluxing $16.73 \mathrm{~g}(50 \mathrm{mmol})$ of 4-tetradecyloxy-2-hydroxybenzaldehyde with $13.50 \mathrm{~g}(50 \mathrm{mmol})$ of $n$-octadecylamine in $n$-heptane for $3 \mathrm{~h}$, with a few drops of glacial acetic acid as the catalyst. The crude product was crystallized several times from hot $n$-heptane. Yield 40\% (11.6 g). ${ }^{1} \mathrm{H}$ NMR (400 MHz, $\left.\mathrm{CDCl}_{3}, \delta \mathrm{ppm}\right): 0.88\left(\mathrm{t}, 6 \mathrm{H}, \mathrm{CH}_{3}\right), 1.10-1.50\left(\mathrm{~m}, 52 \mathrm{H}, \mathrm{CH}_{2}\right), 1.67$ (quintet, $2 \mathrm{H},-\mathrm{CH}_{2}-\mathrm{CH}_{2}-\mathrm{N}$ ), 1.77 (quintet, $2 \mathrm{H},-\mathrm{CH}_{2}-\mathrm{CH}_{2}-\mathrm{O}-$ ), $3.50\left(\mathrm{t}, 2 \mathrm{H},-\mathrm{CH}_{2}-\mathrm{N}-\right), 3.95\left(\mathrm{t}, 2 \mathrm{H},-\mathrm{CH}_{2}-\mathrm{O}-\right), 6.32(\mathrm{dd}, 1 \mathrm{H}$, $\mathrm{H}$-aryl, $\left.J_{\mathrm{m}}=2.5 \mathrm{~Hz}\right), 6.36\left(\mathrm{~d}, 1 \mathrm{H}, \mathrm{H}-\operatorname{aryl}, J_{\mathrm{o}}=8.5 \mathrm{~Hz}, J_{\mathrm{m}}=2.5 \mathrm{~Hz}\right)$, $7.05\left(\mathrm{~d}, 1 \mathrm{H}, \mathrm{H}\right.$-aryl, $\left.J_{\mathrm{o}}=8.5 \mathrm{~Hz}\right), 8.08(\mathrm{~s}, 1 \mathrm{H}, \mathrm{CH}=\mathrm{N}), 14.1(\mathrm{~s}, 1 \mathrm{H}$, $\mathrm{OH})$. Calcd for $\mathrm{C}_{39} \mathrm{H}_{71} \mathrm{NO}_{2}$ : C 79.94, H 12.21, N 2.39. Found: C 80.23, H 12.16, N 2.30.

(d) Synthesis of $\mathrm{La}(\mathrm{III})$ Complex $\left[\mathrm{La}\left(\mathrm{L}{ }_{9} \mathrm{H}\right)_{3}\left(\mathrm{NO}_{3}\right)_{3}\right]$ (5). Compound 5 was prepared by adding a solution of $0.87 \mathrm{~g}(2.00 \mathrm{mmol})$ of La$\left(\mathrm{NO}_{3}\right)_{3} \cdot 6 \mathrm{H}_{2} \mathrm{O}$ in absolute ethanol dropwise to a stirred solution of 1.00 $\mathrm{g}(2.00 \mathrm{mmol})$ of the ligand $\mathrm{L}^{9} \mathrm{H}$ in absolute ethanol, at a temperature not higher than $50{ }^{\circ} \mathrm{C}$. After ca. $15 \mathrm{~min}$, the solution turned cloudy, indicating that the product started to precipitate. Stirring was continued for at least $3 \mathrm{~h}$. The pale yellow precipitate was filtered on a crucible, 
washed with ice-cold absolute ethanol, and dried in vacuo. Yield $84 \%$ $(1.00 \mathrm{~g}) .{ }^{1} \mathrm{H} \mathrm{NMR}\left(250 \mathrm{MHz}, \mathrm{CDCl}_{3}, \delta \mathrm{ppm}\right): 0.88\left(\mathrm{~m}, 6 \mathrm{H}, \mathrm{CH}_{3}\right)$, 1.10-1.40 (m, 40H, $\left.\mathrm{CH}_{2}\right), 1.62\left(\mathrm{~m}, 4 \mathrm{H}, \mathrm{N}-\mathrm{CH}_{2}-\mathrm{CH}_{2}\right.$ and $\mathrm{CH}_{2}-\mathrm{CH}_{2}-$

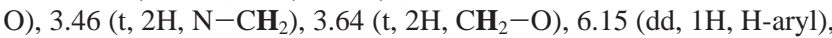
6.33 (d, 1H, H-aryl), 6.90 (d, 1H, H-aryl), $7.60(\mathrm{~d}, 1 \mathrm{H}, \mathrm{CH}=\mathrm{N}), 12.2$ (s, $\left.1 \mathrm{H}, \mathrm{NH}, J_{\mathrm{o}}=8.5 \mathrm{~Hz}, J_{\mathrm{m}}=2.5 \mathrm{~Hz}\right)$. IR (KBr-pellet, $\left.\mathrm{cm}^{-1}\right): 3200$ $(\mathrm{m}, v(\mathrm{NH})), 2920,2860(\mathrm{~s}$, aliphatic $\mathrm{C}-\mathrm{H}$ stretch), $1662(\mathrm{~s}, v(\mathrm{C}=\mathrm{N}))$, $1530(\mathrm{~s}, v(\mathrm{C}=\mathrm{C})), 1475\left(\mathrm{~s}, v_{4}\left(\mathrm{NO}_{3}\right)\right), 1283\left(\mathrm{~s}, v\left(\mathrm{C}_{\mathrm{Ph}}-\mathrm{O}\right)\right.$ and/or $v_{1-}$ $\left.\left(\mathrm{NO}_{3}\right)\right), 1230\left(\mathrm{~s}, v_{\mathrm{as}}(\mathrm{C}-\mathrm{O}-\mathrm{C})\right), 1030\left(\mathrm{~s}, v_{\mathrm{s}}(\mathrm{C}-\mathrm{O}-\mathrm{C})\right), 590(\mathrm{~m}, v(\mathrm{La}-$ O)). Calcd for $\mathrm{C}_{99} \mathrm{H}_{177} \mathrm{~N}_{6} \mathrm{O}_{15} \mathrm{La}$ : C 64.96, H 9.75, N 4.59. Found: C 64.94, H 9.87, N 4.41.

All the other rare-earth complexes were synthesized in an analogous way.

X-ray Crystal Structure Determination of $\left[\mathrm{Dy}\left(\mathrm{L}^{1} \mathrm{H}\right)_{3}\left(\mathrm{NO}_{3}\right)_{3}\right](\mathbf{1})$. Single crystals were obtained by slow isothermal evaporation of a solution of the complex in an ethanol/chloroform (1:1) mixture. The crystals had a yellow color. The data were measured at room temperature $\left(20^{\circ} \mathrm{C}\right)$ on an Enraf-Nonius CAD4 diffractometer (Mo $\mathrm{K} \alpha$ radiation) using a crystal of size $0.2 \times 0.2 \times 0.3 \mathrm{~mm}^{3}$. The unit cell parameters were obtained by the least-squares analysis of a diffractometer angular setting of 25 well-centered reflections in the range $14^{\circ}<\theta<15^{\circ}$. Intensities of 13477 reflections with $2^{\circ}<\theta<$ $26^{\circ}$ were measured by the $\omega / \theta$-scan method, 10305 of them with $I>$ $3 \sigma$. An empirical absorption correction was applied (7 reflections with $\chi \geq 80^{\circ}$ were measured by rotation around the $\psi$-vector with a step of $10^{\circ}$ ). The structure was solved by a direct method using the SIR program..$^{30}$ The difference Fourier synthesis revealed the positions of all hydrogen atoms. The structure was refined by the full-matrix leastsquares method with anisotropic temperature factors for non-hydrogen atoms and isotropic temperature factors for hydrogen atoms. The final difference electron density map showed minimum and maximum values of $0.07(3)$ and $0.32(3) \mathrm{e}^{-3}$. The weighting scheme $w^{-1}=4 F_{\mathrm{o}}{ }^{2} /\left[\sigma(I)^{2}\right.$ $\left.+\left(0.04 F_{\mathrm{o}}^{2}\right)\right]^{2}$ was used in the later stages of the refinement. The final values of the discrepancy indices were $R=0.025$ and $R_{\omega}=0.030$. All calculations were made on the DEC Alpha Station 200 computer by means of the program package MolEN. ${ }^{31}$ A summary of the crystal data, intensity measurements, and crystal structure refinements is reported in Table 2.

X-ray Crystal Structure Determination of $\left[\mathrm{Nd}\left(\mathrm{L}^{1} \mathrm{H}\right)_{3}\left(\mathrm{NO}_{3}\right)_{3}\right]$ (2). Single crystals were obtained by slow isothermal evaporation of a solution of the complex in a hexane/dichloromethane (1:1) mixture.

(30) Altomare, A.; Cascarano, G.; Giacovazzo, C.; Viterbo, D. Acta Crystallogr. 1991, A47, 744.

(31) Straver, L. H.; Schierbeek, A. J. MolEN. Structure Determination System. Nonius B.V.; 1994, Vols. 1 and 2.

(32) SHELXTL-PC, Manual Version 5.1, Bruker Analytical X-ray Systems Inc.: Madison, Wisconsin, 1997.
The crystals had a greenish yellow color. The data were measured at $16{ }^{\circ} \mathrm{C}$ on a Siemens P4-Pc diffractometer (Mo K $\alpha$ radiation) using a crystal of size $0.20 \times 0.25 \times 0.35 \mathrm{~mm}^{3}$. The unit cell parameters were obtained by a least-squares analysis of a diffractometer angular setting of 35 well-centered reflections in the range $7^{\circ}<\theta<13^{\circ}$. Intensities of 7708 reflections with $2^{\circ}<\theta<25^{\circ}$ were measured by the $\omega$-scan method and corrected for absorption (empirical correction based on $\psi$-scans for 12 reflections). The structure was solved by direct methods and refined by full-matrix least-squares on $F^{2}$ using the SHELXTL program package. ${ }^{32}$ Non-hydrogen atoms were anisotropically refined and the hydrogen atoms in the riding mode allowed the $\mathrm{C}-\mathrm{H}$ distances to be refined (except the imino hydrogens, which were localized in the difference Fourier synthesis). The isotropic temperature factors were fixed at 1.2 times $U(\mathrm{eq})$ of the parent atoms. The final $R$-values were $R_{1}=0.0376$ for the observed reflections and $\mathrm{w} R_{2}=0.0971$ for all data (weighting scheme $w^{-1}=\sigma^{2}\left(F_{\mathrm{o}}{ }^{2}\right)+(0.0564 P)^{2}+0.67 P$, where $\left.P=\left[\operatorname{Max}\left(F_{\mathrm{o}}^{2}, 0\right)+2 F_{c}^{2}\right] / 3\right)$. A summary of the crystal data, intensity measurements, and structure refinements is reported in Table 2 .

Acknowledgment. K. Binnemans is Postdoctoral Fellow and L. Van Meervelt is Research Director of the F.W.O.-Flanders (Belgium). K. Binnemans thanks the F.W.O. for a "Krediet aan Navorsers" and Prof. C. Görller-Walrand for laboratory facilities (GOA 98/03 and F.W.O. research grant G.0243.99). R. Van Deun (specialisatiebursaal IWT) is indebted to the "Flemish Institute for the Encouragement of Scientific and Technological Research in the Industry (IWT)" for financial support. K. Binnemans, R. Van Deun and D.W. Bruce wish to thank the British Council and the F.W.O.-Flanders for travel grants (Academic Research Collaboration Program). W. Haase is grateful to the Deutsche Forschungsgemeinschaft for support. D.W. Bruce, Yu. G. Galyametdinov, A. Polishchuk, A.V. Prosvirin and $\mathrm{W}$. Haase are receiving support from the INTASproject (contract INTAS 96-1198). K. Binnemans and Yu. G Galyametdinov wish to thank NATO for a collaborative linkage grant (PST.CLG.974907). Ms. L. Jongen (K.U.Leuven) is acknowledged for TG-DTA measurements and Ms. P. Bloemen (K.U.Leuven) for CHN microanalyses.

Supporting Information Available: $\mathrm{CHN}$ elemental analysis data and melting points of the ligands (Sup-1, PDF) and the CHN data of the complexes (Sup-2) (PDF). An X-ray crystallographic file (CIF). This material is available free of charge via the Internet at http://pubs.acs.org.

JA993351Q 